\title{
Pathological a-synuclein triggers synaptic NMDA receptor dysfunction through altered trafficking
}

\section{Tingting Huang}

Northwest University

De-Hai Gou

Northwestern University

Wen Li

China Medical University

Alexander Svanbergsson

Lunds Universitet

Delphine Bouchet

Centre National de la Recherche Scientifique

Jia-Yi Li

Lunds Universitet

Laurent Groc ( $\square$ laurent.groc@u-bordeaux.fr )

CNRS - University of Bordeaux

\section{Research article}

Keywords: NMDA receptors, lateral diffusion, A53T-a-synuclein, preformed fibril a-synuclein, postsynaptic dysfunction, synucleinopathies

Posted Date: August 6th, 2020

DOI: https://doi.org/10.21203/rs.3.rs-45962/v1

License: (c) (1) This work is licensed under a Creative Commons Attribution 4.0 International License.

Read Full License 


\section{Abstract \\ Background}

a-Synuclein misfolding and aggregation contribute to synaptic dysfunction in synucleinopathies, including Parkinson's disease. However, the mechanism underlying the effect of a-synuclein on synaptic components remains unclear. Since the N-methyl-D-aspartic acid receptor (NMDAR) plays a key role in glutamate synapse pathophysiology, we here investigated its surface dynamics and functional distribution in neurons exposed to various pathological a-synuclein forms.

\section{Methods}

A combination of single-molecule tracking, immunochemistry, immunoblot and calcium imaging approaches were used to assess the changes in NMDAR membrane dynamics and functions. The NMDAR alterations were evaluated in rat cultured hippocampal networks, in which a-synuclein mutants were overexpressed or exposed to a-synuclein proteins (monomeric/PFF a-synuclein). The surface dynamics of NMDAR subtype was artificially tuned in order to test its instrumental role.

\section{Results}

We observed that mutant a-synuclein (A53T-a-synuclein) restricted NMDAR surface trafficking and impaired synaptic function. In contrast, wild-type a-synuclein did not affect synaptic NMDAR. Further, we found that chronic exposure to a-synuclein preformed fibrils induced molecular dysfunctions that mainly targeted the GluN2B-NMDAR subtype. The deficits of synaptic NMDAR have also been found in A53T transgenic mice a-synuclein. Upon fine-tuning of the surface dynamics of GluN2B-NMDAR, pathological a-synuclein gradually lost its synaptic toxicity.

\section{Conclusions}

Our findings indicate that pathological a-synuclein alters GluN2B-NMDAR synaptic dynamics and organization, which leads to glutamate synapse dysfunction.

\section{Background}

Alpha-Synuclein (a-syn) is crucially involved in the formation of abnormal neuronal inclusions, which are known as Lewy bodies or Lewy neurites. These aggregates are hallmarks in several synucleinopathies, including Parkinson's disease (PD), dementia with Lewy bodies (DLB), and multiple system atrophy (MSA) [1]. Previous studies have reported several point mutations, including A53T [2], A30P [3], E46K [4], H50Q [5], G51D [6], and A53E [7], as well as genomic duplications or triplications, in the a-syn locus of patients with familial PD. Further, extracellular a-syn, i.e., fibrillar and oligomerized neuronal forms, could 
be involved in synucleinopathy etiology [8]. However, the mechanism through which pathological a-syn triggers pathogenesis and mediates neuronal and brain network toxicity remains unclear. There are several synaptic feature alterations in early neurodegenerative disease stages, which indicates an involvement of impaired synapse function and degeneration in cognitive decline and disease progression [9-15]. a-Syn localized in the presynaptic compartment can aggregate and induce cellular dysfunction in the presynaptic terminal, including changes in synaptic vesicle recycling and organelle trafficking $[1,16]$. Moreover, a-Syn is found in the postsynaptic compartment; however, its function and involvement in synaptopathies remain unclear.

In the mammalian brain, excitatory neurotransmission is mostly mediated by glutamatergic synapses and activation of ionotropic glutamatergic receptors, including the N-methyl-D-aspartic acid receptor (NMDAR) [17]. NMDARs are heterotetramers made up of different combinations of GluN1, GluN2A-D, and GluN3 subunits, leading to various physiological and pathological properties [18]. Among these subunits, GluN2 subunits are the most crucial in determining the biophysical properties of NMDAR-mediated transmission [19]. GluN2 subunits strongly mediate basal synaptic NMDAR trafficking [20]; moreover, these membrane dynamics are primely involved in synapse plasticity [20,21]. Notably, NMDAR dysregulation has been reported in neuropsychiatric disorders and neurodegenerative diseases [18, 22]. NMDAR expression, activation, and endocytosis are significantly affected in different brain regions in PD animal models and patients [23-30]. Selective NMDAR blockers or antagonists have been shown to improve locomotor activity and ameliorate parkinsonism in several PD models [31-33]. Additionally, there is a correlation of cognitive deficits in PD with brain NMDAR expression [10,34], which suggests that NMDAR-mediated transmission dysregulation is involved in various PD symptoms.

In different PD models, a-syn alters NMDAR expression [11, 27, 35], phosphorylation [35], subcellular localization [11, 34], interactions with scaffold proteins [11, 36], basal transmission [37], as well as NMDAR-mediated long term potentiation (LTP) $[10,27,34]$. The mechanism through which a-syn disturbs NMDAR organization and function remain unclear. This study aimed to investigate the effect of different a-syn forms on NMDAR surface dynamics, synaptic retention, and functions in the hippocampal neuronal networks.

\section{Methods}

\section{Hippocampal neuron culture}

Hippocampal neural cultures were isolated from the embryonic Sprague-Dawley rats on Day 18-19 following a previously described method [38]. In brief, tissues were dissected and collected in dissection medium, which was made up of balanced salt solution containing Penicillin-Streptomycin (PS, Gibco $\# 15140-122$ ) and HEPES (Gibco \#15630-056). The neurons were then dissociated with $0.05 \%$ trypsinethylenediaminetetraacetic acid (Gibco \#25300-054) containing PS and HEPES for 15-20 min. After washing, $3.25 \times 10^{5}$ cells (containing neurons and glial cells) were grown in the $60 \mathrm{~mm}$ Petri dishes on the coverslips pre-coated with poly-L-lysine (PLL, P2636-1G Sigma) with neurobasal medium (Gibco \#12348- 
017) containing SM1 supplement (Stem Cell \#05711), horse serum (GIBCO, \#26050088), and L-glutamine (GIBCO, \#25030-024). The culture medium was replaced by serum-free neurobasal medium after five days of culture in vitro. Cells were maintained at $37^{\circ} \mathrm{C}$ in $5 \% \mathrm{CO}_{2}$ for a maximum of 15 days in vitro.

\section{Animals}

Heterozygote A53T-a-syn transgenic mice (B6; C3-Tg (Prnp-SNCA*A53T) 83Vle/J) were originally obtained in breeding pairs from the Jackson Laboratory (004479). Wild-type mice were C57BL/6J purchased from Liaoning Changsheng biotechnology.co., Ltd (China). All mice in the colony were kept under specific pathogen-free (SPF) conditions in a $14 \mathrm{~h}$ light / $10 \mathrm{~h}$ dark cycle, and had free access to food and water. At 10 months, mice were scarified for protein detections.

\section{Transfection and electroporation}

Neurons were transfected by the method of calcium-phosphate coprecipitation at DIV9-11 as previously described [38]. Briefly, using a mixture solution of Tris-EDTA (TE), $\mathrm{CaCl}_{2}$, and $2 \times \mathrm{HEPES}$-buffered saline, prepared the precipitates with $0.75-1.25 \mu \mathrm{g}$ of plasimidic DNA $(0.25 \mu \mathrm{g}$ of Homer1C-Dsred, $0.5 \mu \mathrm{g}$ wildtype (WT)-/A53T-a-syn, $0.5 \mu \mathrm{g}$ of GluN2A/2B-sep-NMDAR/ GluA1-sep-AMPAR for QD tracking and immunocytochemistry, or $0.5 \mu \mathrm{g}$ of GCaMP6, $0.5 \mu \mathrm{g}$ of WT-/A53T-a-syn for calcium imaging). Coverslips containing neurons were transferred to 12-well plates and incubated with precipitates in $250 \mu$ of conditional medium in the presence of $2 \mathrm{mM}$ kynurenic acid (Sigma-Aldrich \#K3375) for 1-1.5 h. The coverslips were then washed with $2 \mathrm{mM}$ kynurenic acid in unsupplemented neurobasal medium and transferred back to original Petri dishes for four days of overexpression before use.

Neuronal electroporation was performed following the commercial instructions, using the P3 Primary Cell 4D-NucleofectorTM X Kit (LONZA, \#V4XP-3024) and $0.75 \mu \mathrm{g}$ of plasmid DNA (0.25 $\mu \mathrm{g}$ of Homer1C-Dsred and $0.5 \mu \mathrm{g}$ of WT-/A53T-a-syn) to prepare the electro-buffer. The neurons $\left(5 \times 10^{5}\right)$ were resuspended in electro-buffer and transferred to a Single Nucleocuvette ${ }^{\mathrm{T}}$. Using the Amaxa Nucleofector (Lonza), the cells were electroporated with program DC-104. Afterward, the cells were plated on the coverslips and cultured at the $37^{\circ} \mathrm{C}$ in $5 \% \mathrm{CO}_{2}$ for 14 days of overexpression before use.

\section{a-Synuclein treatments}

The overexpression of a-syn (WT/A53T) was processed by either calcium phosphate transfections or the electroporations. Cells at DIV 9-11 were transfected with $0.5 \mu \mathrm{g}$ WT-/A53T-a-syn plasmids via the calcium phosphate method for four days of expression. Or dissociated neurons were electroporated with $0.5 \mu \mathrm{g}$ of WT-/A53T-a-syn plasmids and expressed for 14 days after seeding. To calculate the relative overexpression, we utilized antibody against a-syn to label the a-syn expression in transfected neurons, and the non-transfected neurons in the same coverslip were as basal condition. Then we quantified fluorescence intensity of the a-syn positive signal in every whole neuron, including both cell bodies and dendrites. To perform quantifications, 10 cells were chosen from each condition. 
Proteins of a-syn monomer (\#RP-003) and PFF (\#2015 - 1969) were purchased from Proteos. a-Syn PFF proteins were sonicated at $25 \%$ amplitude $1 \mathrm{~s}$ and $1 \mathrm{~s}$ intervals, 3 min before the application. For an acute exposure, neurons at DIV 13-14 were treated with monomer $(1 \mu \mathrm{M})$ or a-syn PFF $(1 \mu \mathrm{M})$ containing conditional mediums for 20 min (QD experiments) or $1.5 \mathrm{~h}$ (immunostaining) and washed out before experiments. For chronic exposure, a-syn monomers $(1 \mu \mathrm{M})$ or PFF $(1 \mu \mathrm{M})$ were applied to culture medium after transfection at DIV 9-10, and incubated for four days. The concentrations of monomer and PFF were equivalent.

\section{Peptide application}

TAT-peptides[39, 40] [TAT-NS: control, scramble sequence; TAT-GluN2B15: TAT-sequence (YGRKKRRQRRR) - GluN2B C-terminus sequence (NGH VYEKLSSIESDV), CASOL] were administered at $5 \mu \mathrm{M}$ into culture medium of the electroporated neurons, once every other days from DIV7-12, for four applications in total.

\section{Single quantum dots tracking and analysis}

Hippocampal neurons at DIV 13-14 were firstly incubated 10 min with polyclonal antibodies against green fluorescence protein (GFP, Invitrogen, Thermo Fisher 1:100 000) to detect overexpressed GluN2A/2B-sep-NMDAR, followed by 10 min of incubation with QD 655 Goat F(ab')2 anti-rabbit polyclonal antibodies (Invitrogen, Thermo Fisher Scientific Inc.1:50 000). All the cells were incubated in the neurobasal medium supplemented with $1 \%$ bovine serum albumin (BSA) at $37^{\circ} \mathrm{C}$. Coverslips containing neurons were then mounted with Tyrode solution (30 mM D-glucose, $120 \mathrm{mM} \mathrm{NaCl}, 5 \mathrm{mM} \mathrm{KCl}$, $2 \mathrm{mM} \mathrm{MgCl}_{2}, 2 \mathrm{mM} \mathrm{CaCl}_{2}$, and $25 \mathrm{mM} \mathrm{HEPES}, \mathrm{pH}$ 7.3-7.4) as described previously [38] and placed on a heated chamber for observations. Using a mercury lamp and appropriate excitation/emission filters, QD signals were detected with an electron multiplying charged-coupled device (EMCCD) camera (Evolve, Photometrics). Images were obtained every $50 \mathrm{~ms}(20 \mathrm{~Hz})$ with up to 500 consecutive frames and processed using the Metamorph software (Universal Imaging Corporation, PA, USA). In each recording session, 3-4 structured dendritic areas were obtained from every coverslip obtained, and the procedure lasted for up to 20-25 min. a-Syn proteins (monomer or PFF) were incubated for 20 min before QD labeling and acquisitions. The calculations of single QD tracking followed the formulas and the rules described previously $[38,39]$. Briefly, the instantaneous diffusion coefficient ' $D$ ' was calculated for each trajectory, from linear fits of the first four points of the mean-square-displacement versus time function using $\mathrm{MSD}(\mathrm{t})=<\mathrm{r} 2>(\mathrm{t})=4 \mathrm{Dt}$. Using a Vogel algorithm, the two-dimensional trajectories were constructed by correlation analysis between consecutive images. This technique offers high resolution and is capable of measuring the dynamic distribution of GluN2B/2A-NMDAR at synaptic and extra-synaptic sites. A synaptic area was defined as the area with the transfected synaptic marker Homer1C-Dsred. The diffusion coefficient was calculated from GluN2-QD trajectories were present on both the inside and outside of the synaptic area.

\section{Immunocytochemistry}

The following antibodies were used: anti-GFP (Thermo Fisher SCIENTIFIC \#A6455), anti-synaptophysin (Synaptic Systems \#101 011), anti-a-syn (Santa cruz \#sc-12767), anti-myc (Origène \#TA150121). 
All the secondary antibodies were used at $0.1 \mathrm{mg} / \mathrm{mL}$ concentration: anti-rabbit Alexa 488 (Thermo Scientific \#A11008), anti-mouse Alexa 647(Sigma-Aldrich \#F1804).

To detect the endogenous and overexpressed proteins levels, neurons at DIV14 were fixed with $4 \%$ paraformaldehyde (Sigma-Aldrich, \#P6148) in phosphate-buffered saline (PBS) containing 4\% sucrose (Sigma-Aldrich, \#0389) for $15 \mathrm{~min}$ at room temperature (RT), followed by the $5 \mathrm{~min}$ of permeabilization with $0.25 \%$ Triton X-100 in PBS. Non-specific signals were blocked by incubation with $10 \%$ BSA (SIGMA) in PBS for $1 \mathrm{~h}$, after which the cell were incubated with primary antibodies for $2-3 \mathrm{~h}$ at RT, followed by the secondary antibodies for $1 \mathrm{~h}$ at RT. To label the contents of surface glutamatergic receptors (GluN2A/2Bsep- and GluA1-sep-subunit), dissociated hippocampal neurons were live immunostained for 20 min, using anti-GFP antibody at $37^{\circ} \mathrm{C}$. After the fixation, the cells were incubated with secondary antibodies for $1 \mathrm{~h}$ at RT. All the antibodies were prepared in 1\% BSA in PBS. All samples were washed at least three times with PBS between the incubations, finally mounted in the Mowiol mounting medium.

\section{Fluorescence microscopic imaging}

All the neuronal images were acquired using a Photometrics Quantem 512 camera (EMCCD) and MetaMorph imaging software (Molecular Devices) on an inverted confocal spinning-disk microscope (Leica DMI6000B, Leica), using a Leica HCX PL APO CS $60 \times / 1.4$ or $63 \times / 1.4$ oil objective. In each individual experiment, images were captured in the same settings (the same laser intensity and exposure time) across all the samples. Images were exported in the grey scale from individual channels and pseudocolor overlays were prepared using ImageJ software. To perform quantifications, 9-11 cells were chosen from each condition from every independent experiment were chosen. For each neuron, two or three dendritic regions were selected for analysis.

\section{Calcium imaging}

The experiments were performed similarly as formerly described [41]. Briefly, treated hippocampal neurons were transfected with GCaMP6 at DIV 9-10 for four days and transferred to Tyrode solution at least $3 \mathrm{~h}$ before acquisition at DIV 13-14. Before imaging, the cells were incubated in $\mathrm{Mg}^{2+}$-free Tyrode solution supplemented with $5 \mu \mathrm{M}$ Nifedipine (Tocris) and $5 \mu \mathrm{M}$ Bicuculline (Tocris) for $15 \mathrm{~min}$. Time-lapse images were obtained every 50 ms for up to 3000 frames. Thereafter, $50 \mu \mathrm{M}$ D-AP5 was applied directly to the chamber to abolish the calcium transient events. A movie containing another 3000 time-lapse frames was acquired as the baseline for each neuron.

\section{Proteins extraction}

10 months old mice (WT and A53T-a-syn transgenic) were harvested and hippocampus were dissected out and stored at $-80^{\circ} \mathrm{C}$. To extract the protein, tissues were thawed and homogenized in radioimmunoprecipitation assay (RIPA) lysis buffer (Beyotime, \#P0013C) containing 2 mM PMSF (Beyotime, \#ST506) and 1\% protease inhibitor cocktail (Sigma-Aldrich, \#P8340). Following homogenization, samples were centrifuged at $13,000 \mathrm{rpm}$ for $30 \mathrm{~min}$ at $4^{\circ} \mathrm{C}$. The supernatants were collected as protein samples and stored at $-80^{\circ} \mathrm{C}$. 
Synaptosomes components were purified from homogenized hippocampus of 10-month-old WT-and A53T-a-syn transgenic mice, following the methods as previously described [39]. Hippocampal tissues (around $20 \mathrm{mg}$ ) were thawed in $300 \mu \mathrm{L}$ fresh TPS buffer (0.32M sucrose $4 \mathrm{mM}$ HEPES buffer, $\mathrm{pH} 7.4$ ) supplemented with a protease inhibitor cocktail with 15 strokes in glass-Teflon homogenizer $(500 \mu \mathrm{L})$, on the ice. After centrifugation at $1000 \mathrm{~g}$ for $8 \mathrm{~min}$ at $4^{\circ} \mathrm{C}$, the pellet was discarded and the supernatant was centrifuged again at $13,500 \mathrm{~g}$ for $15 \mathrm{~min}$ at $4{ }^{\circ} \mathrm{C}$. The resulting pellet was washed by TPS buffer once and resuspended in RIPA lysis buffer supplemented with protease inhibitor cocktail and PMSF for 15 min lysis. Finally, samples were collected and kept at $-80^{\circ} \mathrm{C}$ for storage.

\section{Western blotting}

The protein content was quantified through BCA assay (Beyotime, \#P0012) and then added $5 \times$ SDS loading buffer (Beyotime, \#P0016) and PBS to gain equal concentration. Before loading, samples were boiled $5 \mathrm{~min}$ at $95^{\circ} \mathrm{C}$. The extractions containing $15 \mu \mathrm{g}$ of protein were separated by SDS/PAGE (Tris-Gly, 4\%-15\% precast gel, Sangon Biotech, \#C651104) for 60 min $150 \mathrm{~V}$, transferred onto polyvinylidene difluoride membranes (Millipore, \#ISEQ00010) and blocked in 5\% skimmed milk (BD, \#232100) for $1 \mathrm{~h}$ and then immunoblotted with specific antibodies. The following primary antibodies were used: antiGluN2A Ab (1:1000, Sigma-Aldrich, \#04-901), anti-GluN2B Ab (1:5000 Abcam, \#ab65783), anti- GluN1 Ab (1:5000, Synaptic Systems, \#114011), anti- GluA1 Ab (1:5000, Synaptic Systems, \#182003), anti-PSD 95 Ab (1:2000 Abcam, \#ab18258), anti-synaptophysin Ab (1:5000, Synaptic Systems, \#101 011), anti- $\beta$-actin Ab (1:10000 Sigma-Aldrich, \#A1978), and diluted in TBST 0.5\% milk overnight at $4{ }^{\circ} \mathrm{C}$. Corresponding secondary antibodies were used at 1:5,000 in TBST $0.5 \%$ milk.

\section{Ethics Statement}

Animal experimentation: All experiments were carried out in accordance with the guidelines and regulations of University of Bordeaux and Northeastern University. The animal procedures were approved by the ethical committee of the University of Bordeaux (Laurent Groc experimentation authorization number 3306009) and Northeastern University, China.

\section{Data and statistical analysis}

All data and statistical analysis was performed by GraphPad Prism 8.00 (GraphPad Software, Inc., La Jolla, CA). Most non-normal data, such as single-particle tracking and immunocytochemistry of the data were assessed by Mann-Whitney test to compare differences between two groups and by Kruskal-wallis test followed by Dunn's Multiple Comparison test between three groups. Normal data such as expression levels using unpaired student's $t$ test. Significance was assessed at $p<0.05$ using two-tails tests unless otherwise specified in the figure legends. Symbols used are: ${ }^{*} p<0.05 ;{ }^{* \star} p<0.001 ;{ }^{* \star} p<0.0001$ throughout the manuscript.

\section{Results}




\section{Wild-type-a-syn overexpression preserves NMDAR surface trafficking and distribution}

Wild-type-a-syn (WT-a-syn) is the physiological a-syn form with concentration- and genetic expressiondependent toxicity $[42,43]$. Given the decreased hippocampal GluN2A/GluN2B subunit ratio in animals with PD [24], we first investigated whether WT-a-syn overexpression could alter GluN2A- and GluN2BNMDAR surface trafficking in hippocampal neurons in active networks. Between 9 and 11 days in vitro, hippocampal neurons were co-transfected with WT-a-syn, Homer1C-Dsred, and/ or GluN2A/2B-sep (sep, superecliptic pHluorin) (Fig. 1). WT-a-syn overexpression led to three-fold a-syn enrichment (Fig. 1a and b, details see Methods). Using antibodies against tagged GluN2 subunits, we performed single-nanoparticle (quantum dot [QD]) tracking on transfected neurons (Fig. 1c). WT-a-syn overexpression did not significantly affect the membrane trafficking of synaptic GluN2A-NMDARs; specifically, there was a slight change in the diffusion coefficients and no effect on the explored area (Fig. 1d and f; Supplemental Fig. 1a ). Moreover, GluN2B-NMDARs maintained similar synaptic surface-trafficking patterns in the presence of WT-a-syn (Fig. 1e and g); however, there was a mild increase in the diffusion of extra-synaptic receptors (Supplemental Fig. 1b). This indicated that WT-a-syn overexpression had no, or very mild, effects on GluN2A- and GluN2B-NMDAR surface trafficking. To determine whether WT-a-syn overexpression altered the synaptic composition of these NMDAR subtypes, we performed live immunostaining of either GluN2A- or GluN2B-NMDARs in hippocampal neurons with identified glutamatergic synapses based on the presence of Homer1C-Dsred clusters (Fig. $1 \mathrm{~h}$ and i). Similar to the minimal effects on NMDAR subtype membrane dynamics, there were no changes in the synaptic GluN2Aand GluN2B-NMDAR content (Fig. 1h and j; Supplemental Fig. 2a and e; Fig. 1i and k; Supplemental Fig. $2 \mathrm{~d}$ and f). Moreover, there were no changes in the postsynaptic Homer1C clusters (Supplemental Fig. 2a, b, $d$ and e). To further confirm this observation, we measured synaptic NMDAR-mediated transmission through spontaneous calcium transients in cultured hippocampal neurons. Based on the neuronally expressed calcium indicator GCaMP6, we imaged calcium events in the presence of an L-type voltage-dependent calcium channel blocker (see Methods). The calcium events were fully stopped by NMDAR-competitive antagonist D-AP5 $(50 \mu \mathrm{M})$, which indicated that they mostly originated from the NMDAR. In neurons that overexpressed WT-a-syn, there was an unaffected frequency of NMDARmediated calcium transients and it was slightly increased compared with the spine populations (Supplemental Fig. 3). Taken together, these findings indicate that a 3-fold increase in WT-a-syn only minimally, if at all, alters NMDAR membrane trafficking and synaptic content.

\section{Mutant A53T-a-syn alters NMDAR surface trafficking and content}

A53T-a-syn is among the earliest reported mutations in synucleinopathies and is known to favor rapid pathological aggregations [44]. Moreover, it has been shown to cause severe movement disorders in A53T transgenic mice $[45,46]$ and to be involved in early-onset familial PD [44]. Furthermore, it has been recently shown to cause learning, memory, and synaptic plasticity deficits [47, 48]; specifically, only A53T- 
mutant, but not WT- or A30P-mutant, a-syn can induce postsynaptic dysfunction in transgenic mice [47]. Consequently, we assessed whether A53T-a-syn could alter NMDAR membrane trafficking and synaptic content. First, we ensured that neuronal expression of WT- and A53T-a-syn were within the same range (Fig. 2a and b, Supplemental Fig. 4). Subsequently, using single-nanoparticle tracking, we assessed whether A53T-a-syn could alter NMDAR surface trafficking. Compared to WT-a-syn, A53T-a-syn significantly decreased GluN2A-NMDAR surface diffusion (Fig. 2d and f right). To further examine GluN2A-NMDAR diffusion patterns, we plotted the mean square displacement (MSD) versus time lag. Compared to WT-a-syn, A53T-a-syn shifted the MSD curve of GluN2A-NMDAR, which indicates a more confined diffusion pattern and smaller explored area (Fig. $2 \mathrm{f}$ left). Moreover, A53T-a-syn significantly reduced GluN2B-NMDAR surface dynamics; however, this was to a smaller extent (Fig. 2e and g). The similar surface trafficking changes in GluN2A- and GluN2B-NMDARs were mainly observed in the synaptic compartment; contrastingly, extra-synaptic receptors had minimal changes (Supplemental Fig. $1 \mathrm{C}$ and d). Taken together, these results show that A53T-a-syn downregulates synaptic GluN2A- and GluN2B-NMDAR surface trafficking, which could involve previously defined aberrant interactions with synaptic partners $[20,40]$.

These altered receptor synaptic dynamics suggest that their retention is possibly also altered. Consequently, we evaluated the synaptic content of GluN2A- and GluN2B-NMDARs using live immunocytochemistry on hippocampal cells. A53T-a-syn-expressing neurons had significantly reduced GluN2A-NMDAR synaptic content; contrastingly, the total membrane amount remained stable (Fig. $2 \mathrm{~h}$ and j, Supplemental Fig. 2a and c). Consistently, A53T-a-syn overexpression significantly decreased the GluN2B-NMDAR synaptic, but not surface, content (Fig. 2i and k, Supplemental Fig. 2d and f). To confirm that A53T-a-syn impaired NMDAR synaptic transmission, we recorded NMDAR-mediated spontaneous calcium transients in WT- and A53T-a-syn-expressing neuron. Consistent with the imaging data, A53T-asyn-expressing neurons had a significantly decreased frequency of NMDAR-mediated spontaneous calcium events (Fig. 3b-d). Compared to WT-a-syn neurons, A53T-a-syn-expressing neurons had a leftshifted cumulative distribution of calcium transient frequency (Fig. 3e). To test whether the A53T-a-syn effect on synaptic NMDARs is specific for this receptor type, we assessed the GluA1-AMPAR synaptic content under similar conditions. Unlike in NMDARs, A53T-a-syn did not alter the surface or synaptic content of GluA1-AMPAR (Fig. 4). Taken together, our findings indicate that A53T-a-syn expression downregulates GluN2A- and GluN2B- NMDAR surface trafficking, as well as their synaptic retention and content, while leaving the AMPAR component intact.

\section{a-Syn preformed fibrils (PFFs) specifically impair GluN2B- NMDAR membrane dynamics}

In sporadic PD, extracellular a-syn, including its fibrillary form, is considered the "toxic seed" and is crucially involved in PD pathogenesis and propagation [1, 49, 50]. Through prion-like propagation [51, 52], toxic proteins are thought to act pre- and post-synaptically in neurotransmission and plasticity impairment. Toxic extracellular a-syn impairs glutamatergic synapse LTP through NMDAR alterations 
[10-12, 27, 34, 36]. Since mutated a-syn impairs synaptic NMDARs (see above), acute neuron exposure to a-syn PFFs (a toxic form of extracellular a-syn [49]) could cause similar NMDAR dysfunction. To assess this question, we examined NMDAR surface trafficking after acute neuron exposure to two different a-syn forms, i.e., monomers or PFFs (concentrations see Methods). Both forms did not alter GluN2A-NMDAR surface diffusion (Fig. 5A upper, B). Notably, a-syn PFFs significantly reduced GluN2B-NMDAR surface diffusion in the synaptic and extrasynaptic compartments (Fig. 5a lower and c). Moreover, a-Syn PFFs affected the MSD curve of GluN2B-NMDAR (Fig. $5 \mathrm{c} \mathrm{left),} \mathrm{which} \mathrm{indicated} \mathrm{that} \mathrm{PFFs} \mathrm{confined} \mathrm{these}$ receptors more. GluN2A- and GluN2B-NMDAR surface and synaptic content remained stable (Fig. 5d-g, Supplemental Fig. 5a-c). However, a-syn PFFs significantly increased the global surface content of GluN2B-NMDARs (Supplemental Fig. 5d-f). Taken together, these findings suggest that acute a-syn PFF administration downregulates GluN2B-NMDAR, but not GluN2A-NMDAR, surface trafficking. This implies a difference in the effect of a-syn PFFs on NMDAR sensitivity or signaling, which is consistent with previous reports $[10,11,35]$. To further study the effects of a-syn PFFs on NMDAR synaptic transmission, we evaluated the NMDAR-mediated spontaneous calcium transients in neurons exposed to acute a-syn PFF or monomer treatment. There was no significant difference in the frequency of calcium transient events and distributions between PFFs and monomers, which indicated that both did not affect NMDARmediated transmission (Fig. 5h-j). Overall, acute a-syn PFF administration could have acute and selective effects on GluN2B-NMDAR surface trafficking and expression.

\section{Chronic neuron exposure to a-syn PFF decreases NMDAR content and function}

Since the effect of a-syn aggregation on synaptic activity and plasticity occurs in a time- and dosedependent manner $[49,50]$, the non-effect of acute a-syn PFF exposure on synaptic NMDAR could have resulted from the short exposure time. To check this, we extended the a-syn PFF incubation time to $48 \mathrm{~h}$ and $96 \mathrm{~h}$ and used calcium imaging and immunochemistry to examine the synaptic NMDARs. After incubation for $48 \mathrm{~h}$, there was a tendency of decreased frequency of NMDAR-mediated calcium transients, which was indicated by the significantly left-shifted cumulative distributions between monomer and PFF (Fig. 6b). Similarly, this was observed after incubation for 96 h; moreover, PFF significantly decreased the NMDAR spontaneous calcium transients (Fig. $6 \mathrm{c}$ and d). These results indicate that chronic ( $96 \mathrm{~h}$ ) exposure to a-syn PFFs reduces NMDAR synaptic content and transmission. These findings were further confirmed via immunochemistry, which indicated decreased GluN2A- and GluN2B-NMDAR synaptic content in neurons exposed to a-syn PFFs compared to those exposed to a-syn monomers (Fig. 6e, f right, $g$, and $h$ right). Notably, there was no effect on GluN2A- and GluN2B-NMDAR membrane contents, which further indicates specific synaptic alterations (Fig. $6 \mathrm{f}$ left, h left, Supplemental Fig. 6). Taken together, our findings indicate that a-syn PFF downregulates NMDARs synaptic content, which is consistent with the deleterious effects of A53T-a-syn.

\section{Hippocampal GluN2A- and GluN2B-NMDAR deficits in A53T-a-syn transgenic mice}

Page 10/30 
To determine whether pathological a-syn induced synaptic NMDAR alterations in an animal model of synucleinopathies, we used Western blotting to quantify hippocampal NMDAR contents in A53T-a-syn transgenic mice (10-month-old). We observed a significant decrease in GluN2A- and GluN2B-NMDAR contents in A53T-a-syn transgenic mice; however, there was no effect on obligatory GluN1 subunits. Moreover, other synaptic components (i.e., GluA1 receptor, PSD95, and synaptophysin) remained stable (Fig. 7a). Notably, we observed a consistent loss of both GluN2A- and GluN2B-NMDAR contents in hippocampal synaptosomes in A53T-a-syn transgenic mice with intact the GluN1 receptors and synaptophysin (Fig. 7b). Taken together, these findings are consistent with our in vitro findings and further indicate that pathological a-syn downregulates GluN2A- and GluN2B- NMDAR synaptic contents.

\section{Modulation of GluN2B-NMDAR surface dynamics rescues the a-syn-mediated effect}

Since we found that the pathological a-syn forms (A53T and PFF) alter NMDAR membrane trafficking and synaptic content, we speculated that these effects could be prevented by NMDAR trafficking, but not ionotropic activity, modulation. First, we confirmed that pathological a-syn expression led to abnormal asyn accumulation and deposition on the cell body [53] (Fig. 8b and c) and glutamatergic synapse loss [54-56] (Fig. 8d and e). Since pathological a-syn reduces NMDAR surface trafficking, especially in the GluN2B-NMDAR subtype (Fig. 5), we assessed whether artificial increasing GluN2B-NMDAR surface dynamics could rescue the synaptic loss mediated by pathological a-syn. To achieve this, we increased GluN2B-NMDAR membrane dynamics using a competing peptide (TAT-2B) that prevented the interaction between the GluN2B-NMDAR C-tail and PDZ scaffold proteins, as previously described [38-40,57]. Although the control non-sense peptide (TAT-NS) did not alter synaptic maker density in A53T-a-synexpressing neurons, TAT-2B significantly increased the synaptic density (both pre- and postsynaptic markers were consistently increased (Fig. 8f). Therefore, increasing GluN2B-NMDAR surface dynamics over several days could prevent A53T-a-syn-mediated synaptic loss, which suggests that NMDAR disorganization by pathological a-syn mediated cellular toxicity and pathology.

\section{Discussion}

Synaptic dysfunctions could reflect early events in synucleinopathies before neuronal death $[10,47,48$, 58]. Therefore, there is a need to understand the molecular mechanism(s) underlying this early effect on synapses. Using a combination of immunocytochemistry, calcium imaging, and single-molecule tracking techniques, we found that pathological a-syn, i.e., A53T-a-syn, impaired NMDAR surface trafficking, and synaptic content. Moreover, a chronic neuron exposure to a-syn PFFs downregulated NMDAR synaptic trafficking and content; further, there was an early specific effect on GluN2B-NMDAR. Artificially increasing GluN2B-NMDAR surface trafficking to counteract the effect of pathological a-syn prevented the deleterious effect of a-syn on synaptic loss. Taken together, our findings support the model where asyn mutations or multimeric conformation alters NMDAR synaptic organization and function. Consequently, this could affect various NMDAR-dependent processes, including synaptic viability. 
Therefore, our findings could lead to the development of novel therapeutic strategies for circumventing NMDAR-dependent synaptic deficits associated with synucleinopathies.

Recent studies have shown that postsynaptic dysfunction is a crucial process correlated with cognitive impairment and dementia in synucleinopathies $[47,48,59]$. Moreover, dendritic spine loss and compromised neuronal and network activities have been observed before neuronal death after exposure to extracellular a-syn (e.g. PFFs) or in a-syn transgenic mice (e.g., A53T and WT-a-syn overexpression) [10, $12,49,50,58-60]$. However, the mechanism through which a-syn abnormalities affect synaptic transmission remains unclear. Our findings are consistent with recent findings that pathological a-syn (i.e., A53T- and a-syn PFF) downregulates NMDAR synaptic content and functions [10, 11, 25, 34, 47]. Our study provides direct molecular evidence that pathological a-syn rapidly alters NMDAR trafficking, which affects the NMDAR synaptic content. Similarly, pathological a-syn has been shown to modulate NMDAR subunit expression [27], impair LTP and basal synaptic transmission [10-12, 34], promote NMDAR phosphorylation [35], and alter interactions with scaffold proteins [36]. We observed that pathological asyn impaired NMDAR surface dynamics. Since surface trafficking and subunit compositions regulate NMDAR signaling [21, 22, 38, 57], our study further indicates that pathological a-syn impairs synaptic NMDARs and NMDAR-dependent functions in the postsynaptic compartment. There is a need for further studies on NMDAR effects induced by other pathological a-syn (e.g. different mutations or oligomers) to better determine the etiology of a-syn mediated effects on synapses.

There is increasing evidence that A53T-a-syn, but not WT-a-syn or other mutations, induces postsynaptic impairment $[47,48]$, a-syn inclusion, $[45,61]$ and neurotoxicity $[45,46]$. Furthermore, individuals with A53T mutation developed a severe PD that is often associated with dementia [62]. This is further indicated by our observation that A53T-a-syn significantly decreased NMDAR. Similarly, chronic exposure to a-syn PFFs downregulated NMDAR synaptic retention and spontaneous activity. This indicates that A53T and chronic exposure to PFFs might modify NMDARs via similar mechanisms. For example, A53T prefers aggregation $[44,45,61]$ and four-day A53T expression allows aggregate formation similar to those induced by PFF. Moreover, oligomeric a-syn has been reported to interact with the membrane protein $\operatorname{PrPC}$ and form complexes with GluN2B-NMDAR, which leads to impaired synaptic function [10]. Decreased NMDAR membrane dynamics and increased GluN2B-NMDAR surface retention after acute treatment with PFFs supports the hypothesis that PFF induces extracellular signaling via GluN2B-NMDAR to impair synaptic function. We reported that PFF a-syn cause NMDAR dysfunction within 4 days, in line with the previously-described seeding effect of PFF a-syn 4 days after administration $[49,63]$. Altogether, these evidences suggest that a-syn, aggregated or not, could impair NMDAR synaptic function.

Aberrant NMDAR surface trafficking [18, 25, 64], distribution, and activity [65] are involved in the emergence of neurological $[66,67]$ and psychiatric disorders $[41,57]$. In our study, we found that pathological a-syn alters NMDAR membrane dynamics. Moreover, artificial NMDAR trafficking manipulation partially rescued a-syn-mediated synaptic loss. Our findings suggest that NMDAR membrane trafficking dysregulation is associated with a-syn mediated etiology. NMDAR surface dynamics can be regulated by endogenous co-agonists [39], PDZ-scaffold proteins (e.g. PSD95) [22, 57], 
extracellular proteins (e.g. reelin, EphrinB) [22], and synaptic activation [21]. Moreover, a-syn-treated and PD models present with changes in the interaction between PSD95 and GluN2-NMDAR $[11,36,68]$. Additionally, GluN2-PSD95 dissociation efficiently promotes neuronal viability in neuropathology $[57,69$, 70]. Taken together, these previous findings suggest that PSD 95 could be a candidate for NMDAR modulation in pathological a-syn conditions. There is a need for studies on the effect of pathological asyn on scaffold proteins (e.g. PSD95) and potential a-syn partners.

\section{Conclusions}

This study provides direct evidence that pathological a-syn impairs synaptic NMDARs through altered surface trafficking. Moreover, our findings suggest that pathological a-syn induces postsynaptic dysfunction by altering synaptic NMDARs. Further, a-syn-mediated synaptic deficits can be partially reversed through surface trafficking manipulation. These findings provide a new perspective for investigating postsynaptic dysfunction in synucleinopathies and could allow a novel therapeutic strategy for circumventing synaptic deficits associated with synucleinopathies.

\section{Abbreviations}

BSA: bovine serum albumin; DLB:dementia with Lewy bodies; EMCCD:electron multiplying chargedcoupled device; GFP:green fluorescence protein; LTP:Iong term potentiation; MSA:multiple system atrophy; NMDAR:N-methyl-D-aspartic acid receptor; PD:Parkinson's disease; QD:quantum dot; RIPA:radioimmunoprecipitation assay; sep:superecliptic pHluorin; TE:Tris-EDTA; WT-a-syn:Wild-type-a-syn

\section{Declarations}

\section{Availability of data and materials}

The datasets used and/or analyzed during the current study are available from the corresponding author on reasonable request.

\section{Ethics approval}

Animal experimentation: All experiments were carried out in accordance with the guidelines and regulations of University of Bordeaux and Northeastern University. The animal procedures were approved by the ethical committee of the University of Bordeaux (Laurent Groc experimentation authorization number 3306009) and Northeastern University, China.

\section{Consent for publication}

Not applicable. 
The authors declare no competing interests.

\section{Funding}

This work is supported by National Natural Science Foundation of China (81430025, U1801681, 31800898), the Key Realm R\&D Program of Guangdong Province (2018B030337001), Swedish Research Council (K2015-61X-22297-03-4; 2019 - 01551), EU-JPND (aSynProtec, REfrAME), EU-H2020-MSCA-ITN2016 (Syndegen), the Strategic Research Area Multipark, National Center for Scientific Research (CNRS), Agence Nationale de la Recherche, and Fondation pour la Recherche Médicale.

\section{Author Contributions}

T.-T.H. and D.-H.G. performed the experiments and analyzed data. A.S. re-built a-syn plasmids. W.L. prepared a-syn proteins. T.-T.H., J.-Y.L. and L.G. conceived and designed the experiments. T.-T.H., D.-H.G. wrote the original manuscript. T.-T.H., D.-H.G., J.-Y.L. and L.G. edited the manuscript. J.-Y.L. and L.G. supervised the whole project. All authors approved the manuscript.

\section{Acknowledgments}

We thank the Bordeaux Imaging Center (service unit of CNRS-INSERM and Bordeaux University, member of the national infrastructure France Biolmaging) for confocal imaging. We also thank culture team of IINS for technical assistance on cell culture and lab members for constructive discussions. We are grateful to Dr. Tiago Fleming Outeiro for a-syn plasmids.

We would like to thank Editage for English language editing.

\section{References}

1. Wong YC, Krainc D. a-synuclein toxicity in neurodegeneration: Mechanism and therapeutic strategies. Nat Med [Internet] Nature Publishing Group. 2017;23:1-13.

2. Polymeropoulos MH, Lavedan C, Leroy E, Ide SE, Dehejia A, Dutra A, et al. Mutation in the a-synuclein gene identified in families with Parkinson's disease. Science. 1997;276:2045-7.

3. Krüger R, Kuhn W, Müller T, Woitalla D, Graeber M, Kösel S, et al. Ala30Pro mutation in the gene encoding a-synuclein in Parkinson's disease. Nat Genet. 1998;18:106-8.

4. Zarranz JJ, Alegre J, Gómez-Esteban JC, Lezcano E, Ros R, Ampuero I, et al. The New Mutation, E46K, of a-Synuclein Causes Parkinson and Lewy Body Dementia. Ann Neurol. 2004;55:164-73.

5. Appel-Cresswell S, Vilarino-Guell C, Encarnacion M, Sherman H, Yu I, Shah B, et al. Alpha-synuclein p.H50Q, a novel pathogenic mutation for Parkinson's disease. Mov Disord. 2013;28:811-3. 
6. Lesage S, Anheim M, Letournel F, Bousset L, Honoré A, Rozas N, et al. G51D a-synuclein mutation causes a novel Parkinsonian-pyramidal syndrome. Ann Neurol. 2013;73:459-71.

7. Pasanen P, Myllykangas L, Siitonen M, Raunio A, Kaakkola S, Lyytinen J, et al. A novel a-synuclein mutation A53E associated with atypical multiple system atrophy and Parkinson's disease-type pathology. Neurobiol Aging. 2014;35:2180.e1-2180.e5.

8. Lee HJ, Bae EJ, Lee SJ. Extracellular a-synuclein-a novel and crucial factor in Lewy body diseases. Nat Rev Neurol Nature Publishing Group. 2014;10:92-8.

9. Tyebji S, Hannan AJ. Synaptopathic mechanisms of neurodegeneration and dementia: Insights from Huntington's disease. Prog Neurobiol Elsevier Ltd. 2017;153:18-45.

10. Ferreira DG, Temido-Ferreira M, Miranda HV, Batalha VL, Coelho JE, Szegö ÉM, et al. a-synuclein interacts with PrP $\mathrm{C}$ to induce cognitive impairment through mGluR5 and NMDAR2B. Nat Neurosci. 2017;20:1569-79.

11. Ferreira DG, Batalha VL, Miranda HV, Coelho JE, Gomes R, Gonçalves FQ, et al. Adenosine A2A receptors modulate a-synuclein aggregation and toxicity. Cereb Cortex. 2017;27:718-30.

12. Diógenes MJ, Dias RB, Rombo DM, Vicente Miranda H, Maiolino F, Guerreiro P, et al. Extracellular alpha-synuclein oligomers modulate synaptic transmission and impair LTP via NMDA-receptor activation. J Neurosci. 2012;32:11750-62.

13. Chen Y, Fu AKY, Ip NY. Synaptic dysfunction in Alzheimer's disease: Mechanisms and therapeutic strategies. Pharmacol Ther Elsevier Inc. 2019;195:186-98.

14. Forner S, Baglietto-Vargas D, Martini AC, Trujillo-Estrada L, LaFerla FM. Synaptic Impairment in Alzheimer's Disease: A Dysregulated Symphony. Trends Neurosci. Elsevier Ltd; 2017;40:347-57.

15. Marttinen M, Kurkinen KM, Soininen H, Haapasalo A, Hiltunen M. Synaptic dysfunction and septin protein family members in neurodegenerative diseases. Mol Neurodegener. 2015;10:1-12.

16. Burré J. The synaptic function of a-synuclein. J. Parkinsons. Dis. 2015. p. 699-713.

17. Sheng M, Hoogenraad CC. The Postsynaptic Architecture of Excitatory Synapses: A More Quantitative View. Annu Rev Biochem. 2007;76:823-47.

18. Lau CG, Zukin RS. NMDA receptor trafficking in synaptic plasticity and neuropsychiatric disorders. Nat Rev Neurosci. 2007;8:413-26.

19. Cull-Candy SG, Leszkiewicz DN. Role of distinct NMDA receptor subtypes at central synapses. Sci. STKE. 2004. p. re16. 19 Oct. 2004.

20. Groc L, Heine M, Cousins SL, Stephenson FA, Lounis B, Cognet $L$, et al. NMDA receptor surface mobility depends on NR2A-2B subunits. Proc Natl Acad Sci U S A. 2006;103:18769-74.

21. Dupuis JP, Ladépêche L, Seth H, Bard L, Varela J, Mikasova L, et al. Surface dynamics of GluN2BNMDA receptors controls plasticity of maturing glutamate synapses. EMBO J. 2014;33:842-61.

22. Ladépêche L, Dupuis JP, Groc L. Surface trafficking of NMDA receptors: Gathering from a partner to another. Semin Cell Dev Biol Elsevier Ltd. 2014;27:3-13. 
23. Xu Y, Yan J, Zhou P, Li J, Gao H, Xia Y, et al. Neurotransmitter receptors and cognitive dysfunction in Alzheimer's disease and Parkinson's disease. Prog Neurobiol Elsevier Ltd. 2012;97:1-13.

24. Costa C, Sgobio C, Siliquini S, Tozzi A, Tantucci M, Ghiglieri V, et al. Mechanisms underlying the impairment of hippocampal long-term potentiation and memory in experimental Parkinson's disease. Brain. 2012;135:1884-99.

25. Navarria L, Zaltieri M, Longhena F, Spillantini MG, Missale C, Spano P, et al. Alpha-synuclein modulates NR2B-containing NMDA receptors and decreases their levels after rotenone exposure. Neurochem Int. Elsevier Ltd; 2015;85-86:14-23.

26. Cheng F, Li X, Li Y, Wang C, Wang T, Liu G, et al. a-Synuclein promotes clathrin-mediated NMDA receptor endocytosis and attenuates NMDA-induced dopaminergic cell death. J Neurochem. 2011;119:815-25.

27. Tozzi A, de lure A, Bagetta V, Tantucci M, Durante V, Quiroga-Varela A, et al. Alpha-Synuclein Produces Early Behavioral Alterations via Striatal Cholinergic Synaptic Dysfunction by Interacting With GluN2D N-Methyl-D-Aspartate Receptor Subunit. Biol Psychiatry Elsevier. 2016;79:402-14.

28. Mellone M, Zianni E, Stanic J, Campanelli F, Marino G, Ghiglieri V, et al. NMDA receptor GluN2D subunit participates to levodopa-induced dyskinesia pathophysiology. Neurobiol Dis. 2019;121:33849.

29. Zhu M, Cortese GP, Waites CL. Parkinson's disease-linked Parkin mutations impair glutamatergic signaling in hippocampal neurons. BMC Biol [Internet] BMC Biology. 2018;16:100.

30. Hallett PJ, Dunah AW, Ravenscroft P, Zhou S, Bezard E, Crossman AR, et al. Alterations of striatal NMDA receptor subunits associated with the development of dyskinesia in the MPTP-lesioned primate model of Parkinson's disease. Neuropharmacology. 2005;48:503-16.

31. Johnson K, Conn P, Niswender C. Glutamate Receptors as Therapeutic Targets for Parkinsons Disease. CNS Neurol Disord - Drug Targets. 2012;8:475-91.

32. Nash JE, Hill MP, Brotchie JM. Antiparkinsonian actions of blockade of NR2B-containing NMDA receptors in the reserpine-treated rat. Exp Neurol. 1999;155:42-8.

33. Steece-Collier K, Chambers LK, Jaw-Tsai SS, Menniti FS, Greenamyre JT. Antiparkinsonian actions of CP-101,606, an antagonist of NR2B subunit- containing N-methyl-D-aspartate receptors. Exp Neurol. 2000;163:239-43.

34. Durante V, De lure A, Loffredo V, Vaikath N, De Risi M, Paciotti S, et al. Alpha-synuclein targets GluN2A NMDA receptor subunit causing striatal synaptic dysfunction and visuospatial memory alteration. Brain. 2019;142:1365-85.

35. Yang J, Hertz E, Zhang X, Leinartaité L, Lundius EG, Li J, et al. Overexpression of a-synuclein simultaneously increases glutamate NMDA receptor phosphorylation and reduces glucocerebrosidase activity. Neurosci Lett Elsevier Ireland Ltd. 2016;611:51-8.

36. Emanuele M, Esposito A, Camerini S, Antonucci F, Ferrara S, Seghezza S, et al. Exogenous AlphaSynuclein Alters Pre- and Post-Synaptic Activity by Fragmenting Lipid Rafts. EBioMedicine The Authors. 2016;7:191-204. 
37. Franco R, Aguinaga D, Reyes I, Canela El, Lillo J, Tarutani A, et al. N-Methyl-D-Aspartate Receptor Link to the MAP Kinase Pathway in Cortical and Hippocampal Neurons and Microglia Is Dependent on Calcium Sensors and Is Blocked by a-Synuclein, Tau, and Phospho-Tau in Non-transgenic and Transgenic APPSw,Ind Mice. Front Mol Neurosci. 2018;11:1-14.

38. Kellermayer B, Ferreira JS, Dupuis J, Levet F, Grillo-Bosch D, Bard L, et al. Differential Nanoscale Topography and Functional Role of GluN2-NMDA Receptor Subtypes at Glutamatergic Synapses. Neuron. 2018;100:106-19.e7.

39. Ferreira JS, Papouin T, Ladépêche L, Yao A, Langlais VC, Bouchet D, et al. Co-agonists differentially tune GluN2B-NMDA receptor trafficking at hippocampal synapses. Elife. 2017;6:1-22.

40. Barda L, Sainlos M, Bouchet D, Cousins S, Mikasova L, Breillat C, et al. Dynamic and specific interaction between synaptic NR2-NMDA receptor and PDZ proteins. Proc Natl Acad Sci U S A. 2010;107:19561-6.

41. Jézéquel J, Johansson EM, Dupuis JP, Rogemond V, Gréa H, Kellermayer B, et al. Dynamic disorganization of synaptic NMDA receptors triggered by autoantibodies from psychotic patients. Nat Commun Springer US. 2017;8:1791.

42. 42.

43. Ulusoy A, Di Monte DA. a-Synuclein elevation in human neurodegenerative diseases: experimental, pathogenetic, and therapeutic implications. Mol. Neurobiol. 2013. p. 484-94.

44. Conway KA, Harper JD, Lansbury PT. Accelerated in vitro fibril formation by a mutant a-synuclein linked to early-onset Parkinson disease. Nat Med. 1998;4:1318-20.

45. Giasson BI, Duda JE, Quinn SM, Zhang B, Trojanowski JQ, Lee VMY. Neuronal a-synucleinopathy with severe movement disorder in mice expressing A53T human a-synuclein. Neuron. 2002;34:52133.

46. Lee MK, Stirling W, Xu Y, Xu E, Qui D, Mandir AS, et al. Human a-synuclein-harboring familial Parkinson's disease-linked Ala-53 $\rightarrow$ Thr mutation causes neurodegenerative disease with asynuclein aggregation in transgenic mice. Proc. Natl. Acad. Sci. U. S. A. 2002. p. 8968-73.

47. Teravskis PJ, Covelo A, Miller EC, Singh B, Martell-Martínez HA, Benneyworth MA, et al. A53t mutant alpha-synuclein induces tau-dependent postsynaptic impairment independently of neurodegenerative changes. J Neurosci. 2018;38:9754-67.

48. Singh B, Covelo A, Martell-Martínez H, Nanclares C, Sherman MA, Okematti E, et al. Tau is required for progressive synaptic and memory deficits in a transgenic mouse model of a-synucleinopathy. 138. Berlin Heidelberg: Acta Neuropathol. Springer; 2019. pp. 551-74.

49. Volpicelli-Daley LA, Luk KC, Patel TP, Tanik SA, Riddle DM, Stieber A, et al. Exogenous a-Synuclein Fibrils Induce Lewy Body Pathology Leading to Synaptic Dysfunction and Neuron Death. Neuron [Internet]. Elsevier Inc.; 2011;72:57-71.

50. Wu Q, Takano H, Riddle DM, Trojanowski JQ, Coulter DA, Lee VMY. a-Synuclein (asyn) preformed fibrils induce endogenous asyn aggregation, compromise synaptic activity and enhance synapse loss in cultured excitatory hippocampal neurons. J Neurosci. 2019;39:5080-94. 
51. Leak RK, Frosch MP, Beach TG, Halliday GM. Alpha-synuclein: prion or prion-like? Acta Neuropathol. 138. Berlin Heidelberg: Springer; 2019. pp. 509-14.

52. Angot E, Steiner JA, Hansen C, Li JY, Brundin P. Are synucleinopathies prion-like disorders? Lancet Neurol. Elsevier Ltd; 2010;9:1128-38.

53. Spillantini MG, Schmidt ML, Lee VM, Trojanowski JQ, Jakes R, Goedert M. Alpha-synuclein in Lewy bodies [letter]. Nature. Macmillan Magazines Ltd.; 1997;388:839-40.

54. Prots I, Grosch J, Brazdis RM, Simmnacher K, Veber V, Havlicek S, et al. a-Synuclein oligomers induce early axonal dysfunction in human iPSC-based models of synucleinopathies. Proc Natl Acad Sci U S A. 2018;115:7813-8.

55. Bellucci A, Mercuri NB, Venneri A, Faustini G, Longhena F, Pizzi M, et al. Parkinson's disease: From synaptic loss to connectome dysfunction. Neuropathol Appl Neurobiol. 2016;42:77-94.

56. Henstridge CM, Pickett E, Spires-Jones TL. Synaptic pathology: A shared mechanism in neurological disease. Ageing Res Rev Elsevier BV. 2016;28:72-84.

57. Bard L, Groc L. Glutamate receptor dynamics and protein interaction: Lessons from the NMDA receptor. Mol Cell Neurosci Elsevier Inc. 2011;48:298-307.

58. Froula JM, Henderson BW, Gonzalez JC, Vaden JH, Mclean JW, Wu Y, et al. a-Synuclein fibril-induced paradoxical structural and functional defects in hippocampal neurons. Acta Neuropathol Commun. 2018;6:35.

59. Blumenstock S, Angelo MF, Peters F, Dorostkar MM, Ruf VC, Luckner M, et al. Early defects in translation elongation factor 1 a levels at excitatory synapses in a-synucleinopathy. 138. Berlin Heidelberg: Acta Neuropathol. Springer; 2019. pp. 971-86.

60. Blumenstock S, Rodrigues EF, Peters F, Blazquez-Llorca L, Schmidt F, Giese A, et al. Seeding and transgenic overexpression of alpha-synuclein triggers dendritic spine pathology in the neocortex. EMBO Mol Med. 2017;9:716-31.

61. Sacino AN, Brooks M, Thomas MA, McKinney AB, McGarvey NH, Rutherford NJ, et al. Amyloidogenic a-synuclein seeds do not invariably induce rapid, widespread pathology in mice. Acta Neuropathol. 2014;127:645-65.

62. Goedert M, Jakes R, Spillantini MG. The Synucleinopathies: Twenty Years on. J Parkinsons Dis. 2017;7:53-71.

63. Volpicelli-Daley LA, Luk KC, Lee VMY. Addition of exogenous a-synuclein preformed fibrils to primary neuronal cultures to seed recruitment of endogenous a-synuclein to Lewy body and Lewy neurite-like aggregates. Nat Protoc. 2014;9:2135-46.

64. Groc L, Bard L, Choquet D. Surface trafficking of N-methyl-d-aspartate receptors: Physiological and pathological perspectives. Neuroscience IBRO. 2009;158:4-18.

65. Paoletti P, Bellone C, Zhou Q. NMDA receptor subunit diversity: Impact on receptor properties, synaptic plasticity and disease. Nat. Rev. Neurosci. 2013. p. 383-400. 
66. Chang L, Zhang Y, Liu J, Song Y, Lv A, Li Y, et al. Differential Regulation of N-Methyl-D-Aspartate Receptor Subunits is An Early Event in the Actions of Soluble Amyloid- $\beta 1-40$ Oligomers on Hippocampal Neurons. J Alzheimer's Dis. 2016;51:197-212.

67. Picconi B, Piccoli G, Calabresi P. Synaptic dysfunction in Parkinson's disease. Adv Exp Med Biol. 2012;970:553-72.

68. Gardoni F, Picconi B, Ghiglieri V, Polli F, Bagetta V, Bernardi G, et al. A critical interaction between NR2B and MAGUK in L-DOPA induced dyskinesia. J Neurosci. 2006;26:2914-22.

69. Ittner LM, Ke YD, Delerue F, Bi M, Gladbach A, van Eersel J, et al. Dendritic function of tau mediates amyloid- $\beta$ toxicity in alzheimer's disease mouse models. Cell. 2010;142:387-97.

70. Aarts M, Liu Y, Liu L, Besshoh S, Arundine M, Gurd JW, et al. Treatment of ischemic brain damage by perturbing NMDA receptor-PSD-95 protein interactions. Science. 2002;298:846-50.

\section{Figures}


Fig.1 Overexpression of wild-type a-sya preserves NMDAR surface trafficking and distribution.
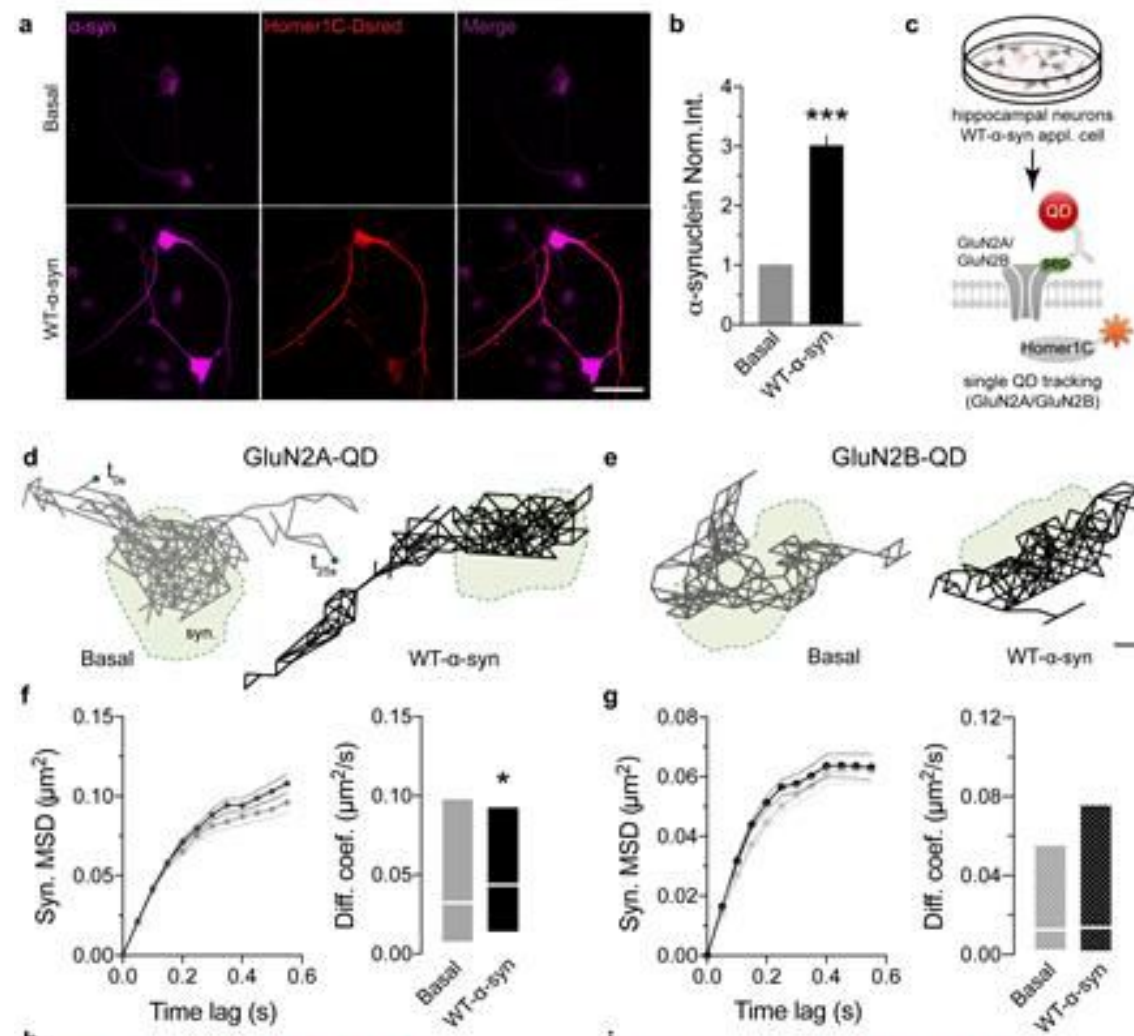

h
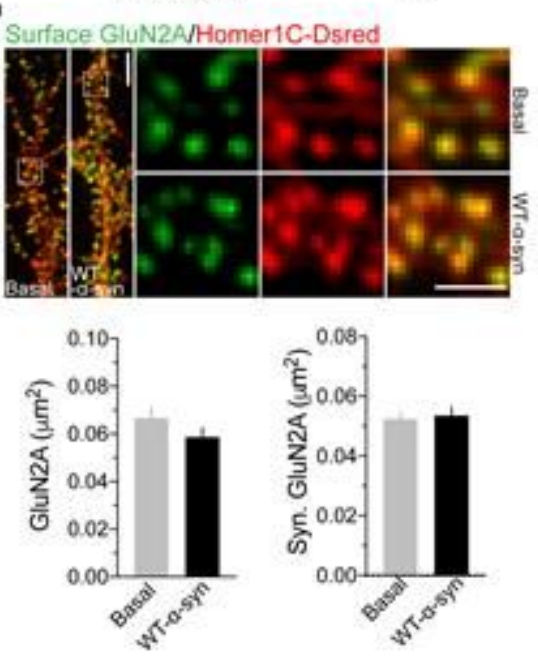

GluN2B-QD

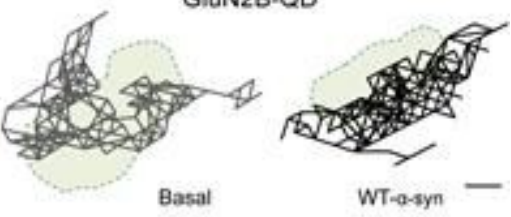

9
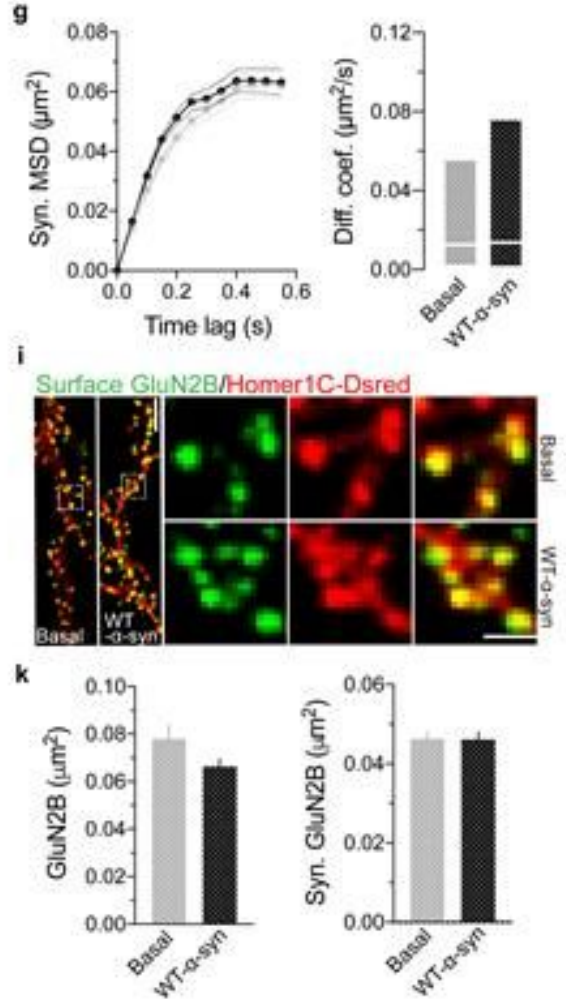

Figure 1

Wild-type a-syn overexpression preserves NMDAR trafficking and distribution. a a-Syn immunostaining of basal (endogenous expression) and WT-a-syn-overexpressing neurons (co-transfected Homer1C-Dsred) at DIV 14 (scale $=20 \mu \mathrm{m}$ ). b Quantification of a-syn fluorescence intensity normalized to basal condition (nBasal $=31$ cells, nWT-a-syn $=33$ cells, $* * * p<0.0001$, unpaired t test). $c$ Schematic representation of transfected neurons expressing WT-a-syn and/or sep-tagged GluN2 and Homer1C-Dsred. Quantum dot (QD) was coupled to a specific antibody to detect single surface GluN2-NMDAR in transfected neurons (labeled by Homer1C-Dsred). d Representative surface trajectories ( 25 s duration) of single QD-coupled GluN2A-NMDAR in the synaptic area. e Representative surface trajectories of single QD-coupled GluN2BNMDAR in the synaptic area $($ scale $=200 \mathrm{~nm}) . \mathrm{f}$ Left panel: MSD of surface synaptic GluN2A trajectories 
either in basal (grey) or WT-a-syn (black) conditions. Right panel: The instantaneous diffusion coefficient of synaptic GluN2A-QD (nBasal $=705, n W T-a-s y n=798$ trajectories; ${ }^{*} p=0.0130$, Mann Whitney test). $\mathrm{g}$ Left panel, MSD of surface GluN2B trajectories as in ( $f$ ). Right panel: Instantaneous diffusion coefficient of synaptic GluN2B-QD as in (f). (nBasal $=782$, nWT-a-syn $=971$ trajectories; $p=0.2973$, Mann Whitney test.) h GluN2A-NMDAR surface labeling in hippocampal neurons at DIV 13-14 under basal or WT-a-syn overexpression. Homer $1 \mathrm{C}$ staining was used as the synaptic maker (left panel, scale $=5 \mu \mathrm{m}$ ). Enlarged Homer1C or GluN2A cluster images (right panels, scale $=1 \mu \mathrm{m}$ ). i GluN2B-NMDAR surface labeling in the hippocampal culture as in (h). j Left panel, comparison of the surface GluN2A cluster areas (nBasal $=80$ segments, $n W T-a-s y n=84$ segments; $p=0.0744$, Mann Whitney test). Right panel: Area of surface synaptic GluN2A clusters, measured by GluN2A clusters overlapping with Homer $1 \mathrm{C}$ positive clusters $(\mathrm{p}=$ 0.7477, Mann Whitney test). $k$ Left panel: Area of surface GluN2B clusters (nBasal $=78$ segments, nWT-asyn $=85$ segments; $p=0.3788$, Mann Whitney test). Right panel: Area of surface synaptic GluN2B clusters, as described in (j) ( $p=0.6719$, Mann Whitney test). Results in (b), ( $f$ left), ( $g$ left), (j), and $(k)$ are expressed as mean \pm SEM while those in ( $f$ right) and ( $g$ right) are expressed as median $\pm 25 \%-75 \%$ interquartile range (IQR) ( $\mu \mathrm{m} 2 \mathrm{~s}-1)$. 
Fig.2 Mutant A53T $\alpha$-5yn alters NMDAR surface trafficking and content

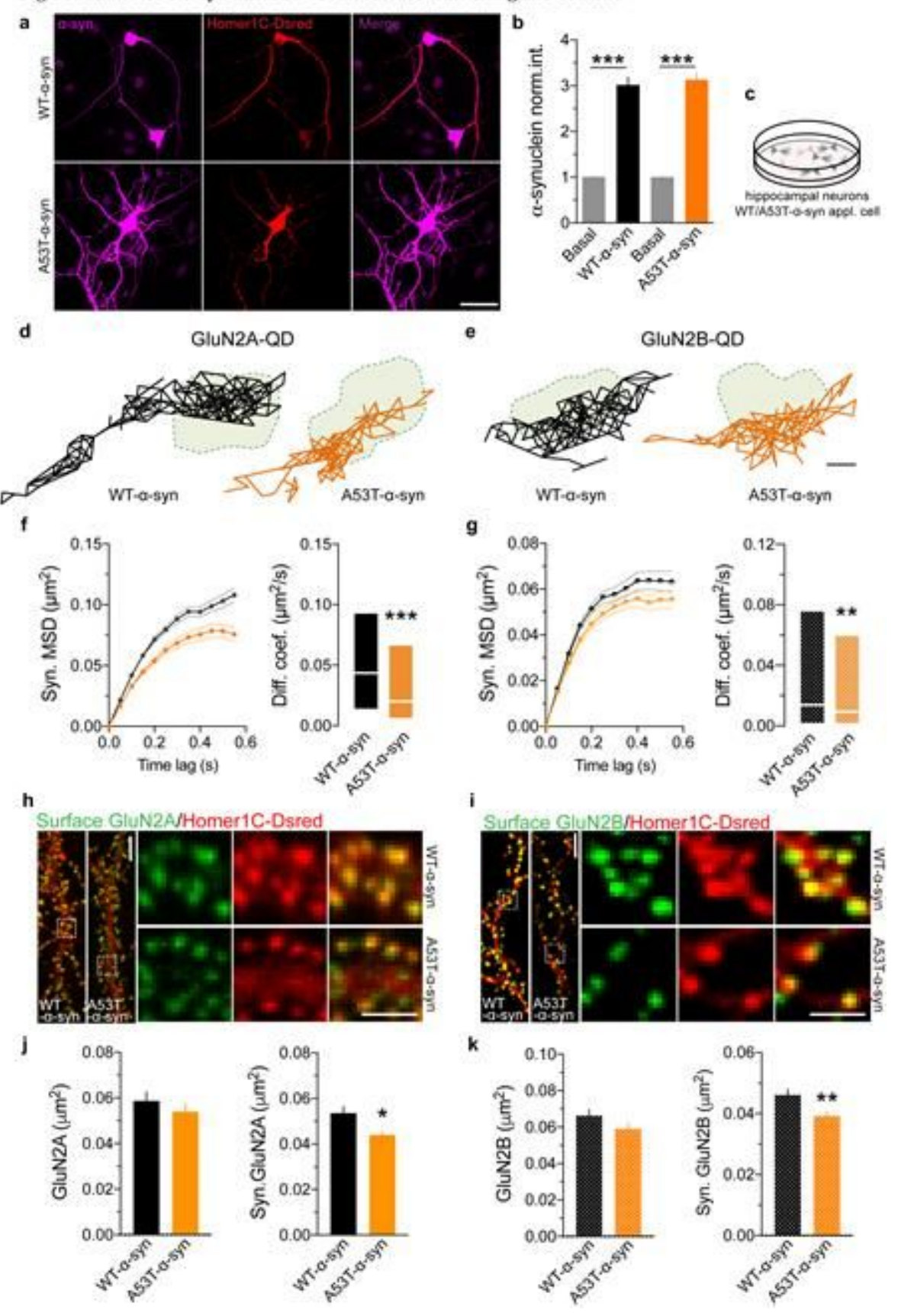

\section{Figure 2}

Mutant A53T a-syn alters NMDAR surface trafficking and content. a a-Syn immunostaining in WT- or A53T-a-syn overexpressing neurons (co-transfected Homer1C-Dsred) at DIV 14 (scale $=20 \mu \mathrm{m}$ ). b a-Syn fluorescence intensity quantification with normalization to respective control condition (nBasal $=31$ cells, nWT-a-syn = 33 cells; $* \star \star p<<0.0001$, nBasal $=33$, nA53T-a-syn = 33; $* \star \star p<<0.0001$, Unpaired t test). c Schematic representation of transfected WT-/A53T-a-syn-expressing neurons co-transfected with Homer1C-Dsred and tagged GluN2-NMDAR. d Representative surface trajectories of single QD-coupled GluN2A-NMDAR in the synaptic area $($ scale $=200 \mathrm{~nm}$ ). e Representative surface trajectories of single QDcoupled GluN2B-NMDAR as in (d). f MSD of synaptic GluN2A-QD trajectories in WT-a-syn (black) or A53Ta-syn (orange) conditions. Comparison of instantaneous diffusion coefficients of synaptic GluN2A-QD 
(nWT-a-syn $=798$ trajectories, nA53T-a-syn $=598$ trajectories, ${ }^{\star \star \star} \mathrm{p}<0.0001$, Mann Whitney test). g MSD of synaptic GluN2B-QD trajectories as in ( $f$ ). Comparison of instantaneous diffusion coefficients of synaptic GluN2B-QD trajectories as in (f) (nWT-a-syn = 971 trajectories, nA53T-a-syn = 844 trajectories; $\star * p=0.0058$, Mann Whitney test). h GluN2A-NMDAR surface labeling in WT-/A53T-a-syn-overexpressing hippocampal neurons at DIV 13-14. Homer 1C-Dsred staining was used as the synaptic maker (left, scale $=5 \mu \mathrm{m}$ ). Enlarged Homer1C or GluN2A cluster images (right panels, scale $=1 \mu \mathrm{m}$ ). i GluN2B-NMDAR surface labeling in hippocampal culture as in (h). $\mathrm{j}$ Comparisons of surface and synaptic GluN2A cluster areas. (nWT- $a$-syn $=84$ segments, $n$ A53T- $a$-syn $=83$ segments, $p=0.3382 ;{ }^{*} p=0.0189$, Mann Whitney test). $\mathrm{k}$ Comparisons of surface and synaptic GluN2B cluster areas (nWT-a-syn $=85$ segments, $\mathrm{n}$ A53T-asyn $=79$ segments; $p=0.1211,{ }^{\star *} p=0.0074$, Mann Whitney test). Results in (b), (f left), (g left), (j), and (k) are expressed as mean \pm SEM while those in (f right) and (g right) are expressed as median $\pm 25 \%-75 \%$ interquartile range (IQR) ( $\mu \mathrm{m} 2 \mathrm{~s}-1)$.

Fig. 3: Mutant A53T- $\alpha$-syn impairs the synaptic transmission of NMDARs.

a
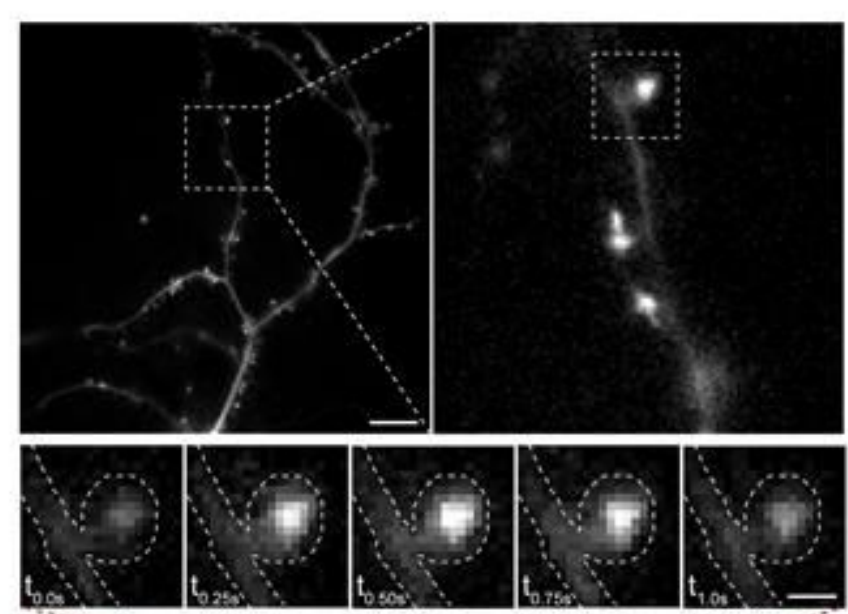

b
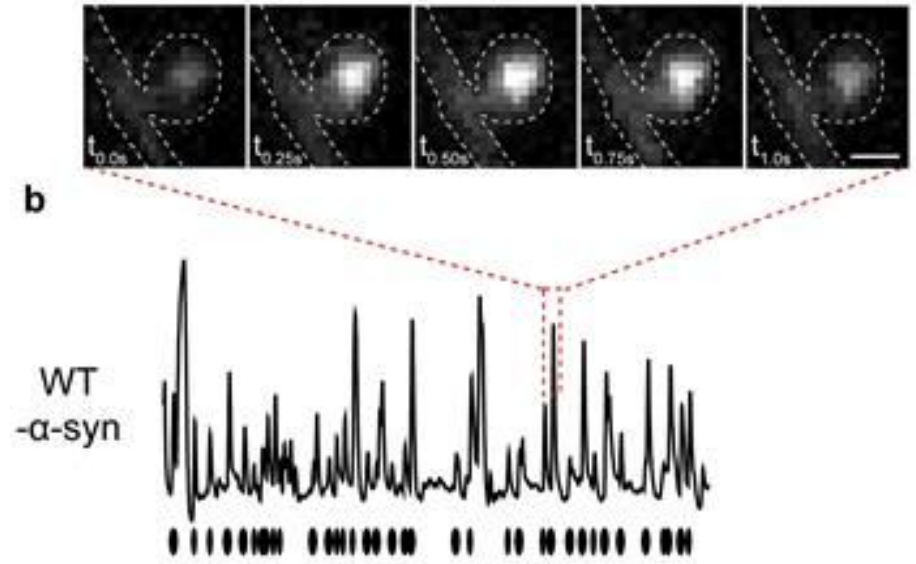

c

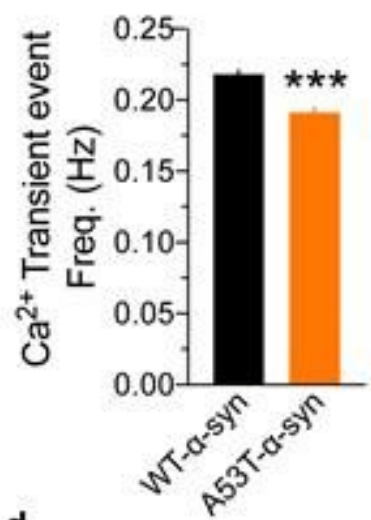

d

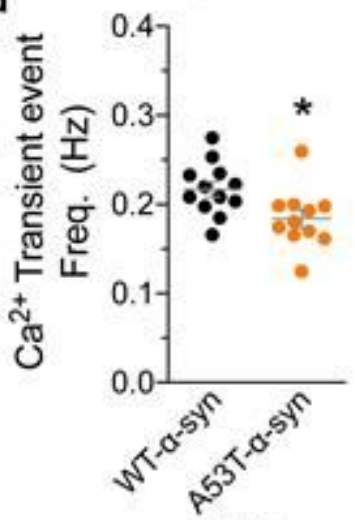

A53T

- $\mathrm{a}-\mathrm{syn}$

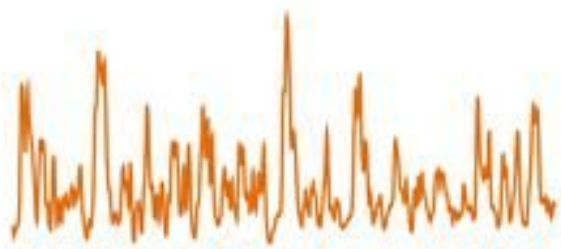

01010 40 101001 11 100010

D-AP5

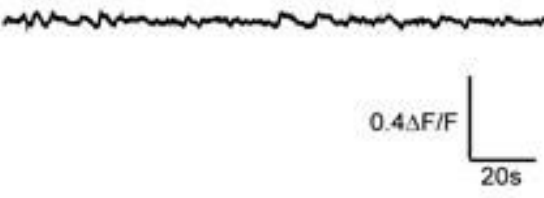

e

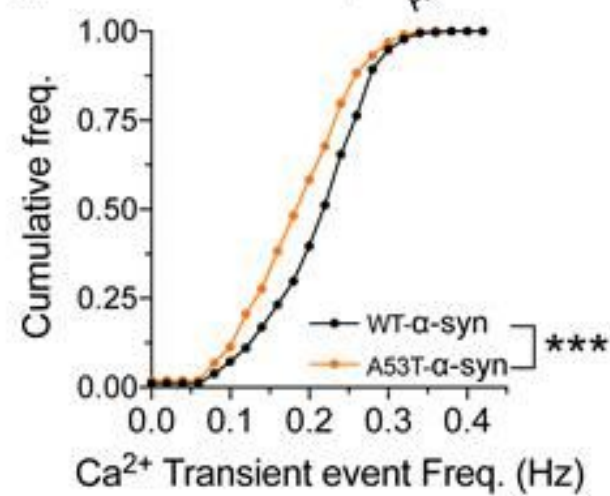




\section{Figure 3}

Mutant A53T-a-syn impairs the synaptic transmission of NMDARs. a Left panel: Dendritic segment calcium imaging in basal condition (in the presence of nifedipine $5 \mu \mathrm{M}$ and bicuculline $5 \mu \mathrm{M}$ ) (scale $=20$ $\mu \mathrm{m})$. Right panel: enlarged dendritic segment image with the dotted square representing an individual spine (scale $=5 \mu \mathrm{m})$. Lower panel: Representative time-lapse images of a spontaneous NMDAR-mediated calcium transient in basal condition (scale $=1 \mu \mathrm{m}$ ). b Representative examples of NMDAR-mediated spinal calcium transients (expressed as $\triangle F / F$ ratio) in WT-/A53T-a-syn-expressing neurons. Notably, all the events were abolished by the NMDAR-competitive antagonist D-AP5 $(50 \mu \mathrm{M})$. c Mean calcium transient frequency of all the spines in the respective conditions (: nWT-a-syn $=464$ spines, $n$ A53T-a-syn $=343$ spines; ${ }^{* \star} p<0.0001$, Mann Whitney test). $\mathrm{d}$ Mean calcium transient frequency of each neuron in the respective conditions ( $\mathrm{n}$ WT-a-syn $=12$ cells, $\mathrm{nA53T}$ - $\mathrm{a}$-syn $=11$ cells; ${ }^{*} \mathrm{p}=0.0106$, Mann Whitney test). e Frequency distributions of calcium transient events of all spines in WT-/A53T a-syn-overexpressing neurons. The results in (C) and (D) are expressed as mean \pm SEM.

\section{Fig. 4: Mutant A53T- $\alpha$-syn preserves surface content of AMPA receptors.}

a

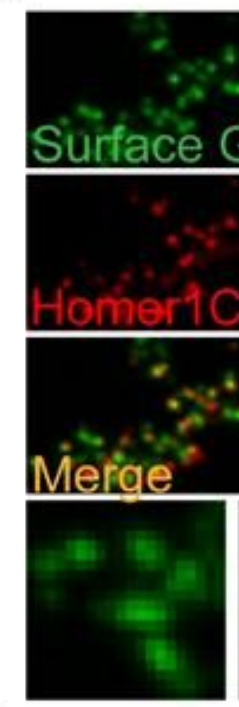

Basal

\section{Basers}

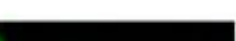

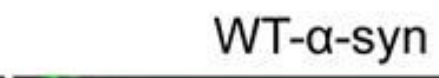
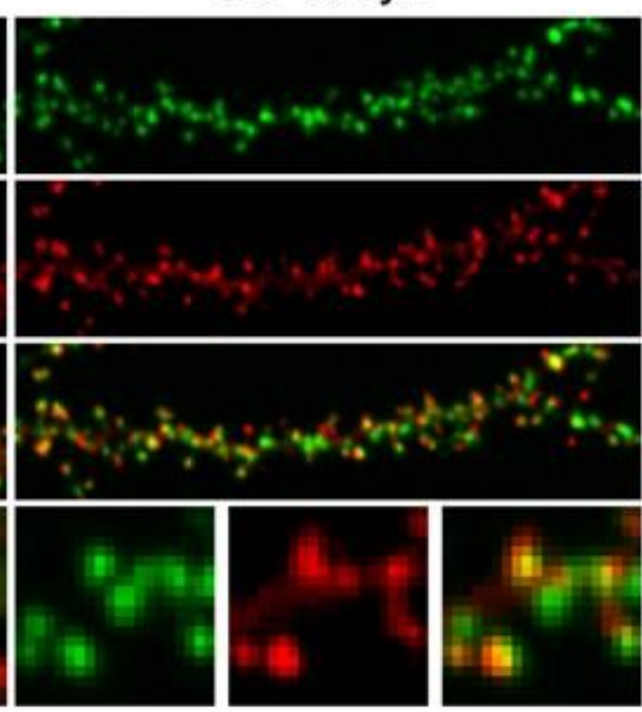

b

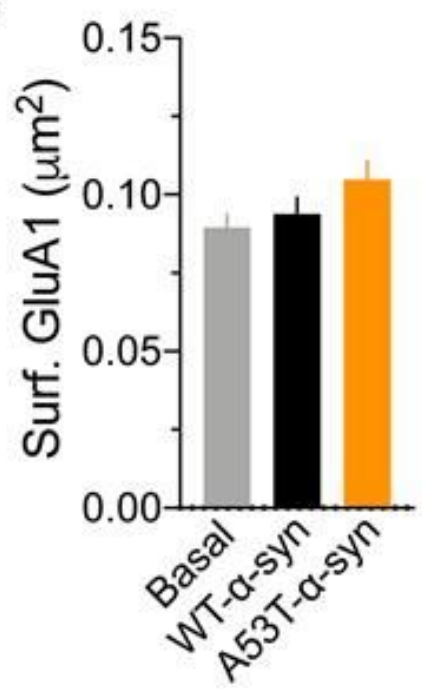

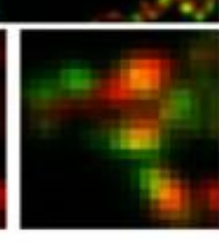

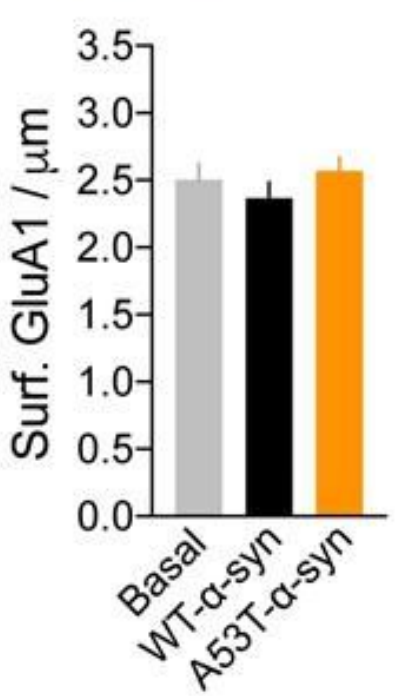

c

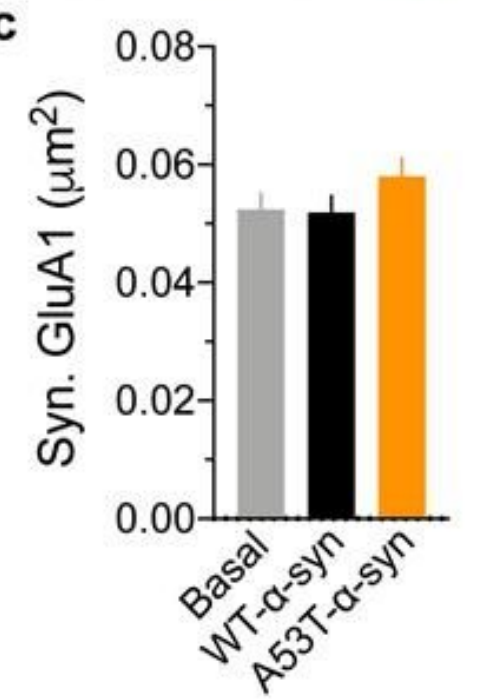

A53T-a-syn
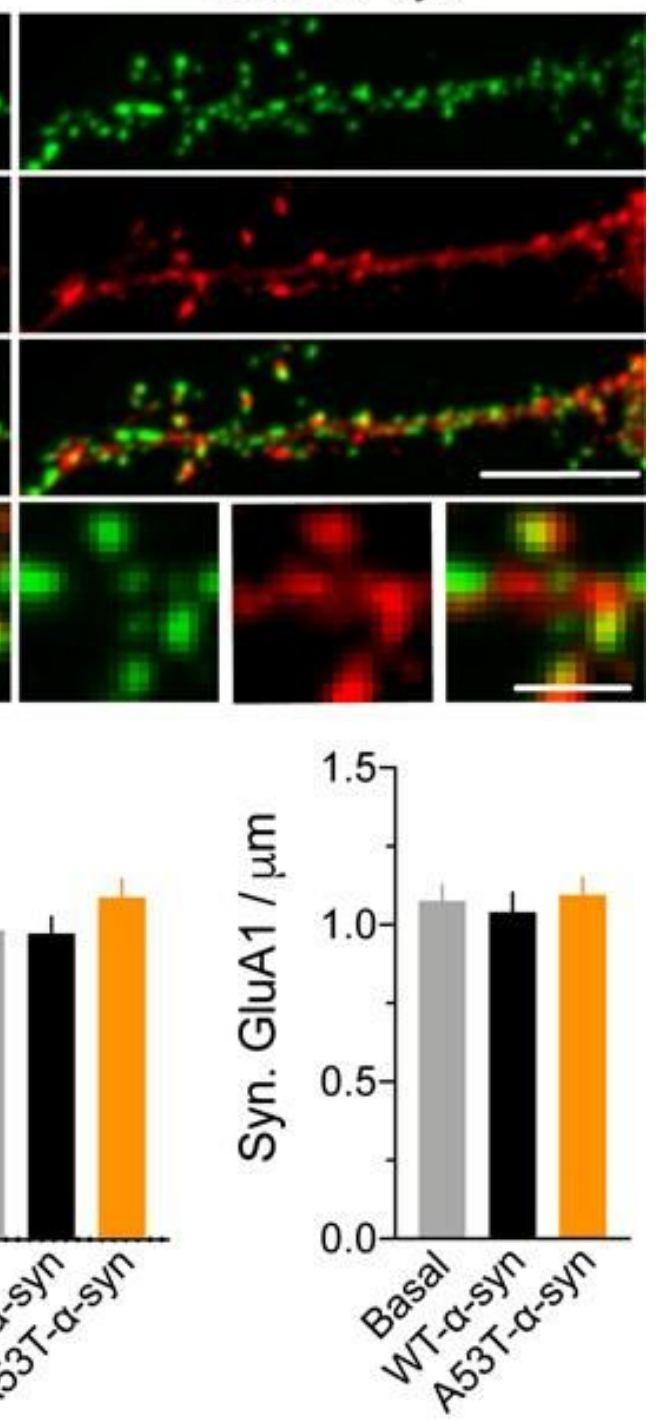


\section{Figure 4}

Mutant A53T-a-syn preserves AMPAR surface content. a GluA1-AMPAR surface labeling in hippocampal neurons at DIV 13-14 under basal or WT-/A53T-a-syn overexpression conditions. Homer 1C staining was used as the synaptic maker (upper panels, scale $=5 \mu \mathrm{m}$ ). Enlarged Homer1C or GluA1 cluster images (lower panels, scale $=1 \mu \mathrm{m}$ ). b Comparisons of the surface GluA1 cluster area and linear density in the respective conditions ( $n$ Basal $=57$ segments, $n W T-a-s y n=54$ segments, $n A 53 T-a-s y n=54$ segments; $p=$ $0.2043 ; p=0.2865$, Kruskal-Wallis test followed by Dunn's multiple comparisons test). $c$ Comparison of the surface synaptic GluA1 cluster area and linear density in the respective conditions (nBasal = 57 segments, $n W T-a-s y n=54$ segments, $n A 53 T-a-s y n=54$ segments; $p=0.2819 ; p=0.5296$, Kruskal-Wallis test followed by Dunn's multiple comparisons test). The results in (b) and (c) are expressed as mean \pm SEM.

Fig. $5 \alpha$-syn PFF impairs specifically the membrane dynamics of GluN2B-NMDAR

a

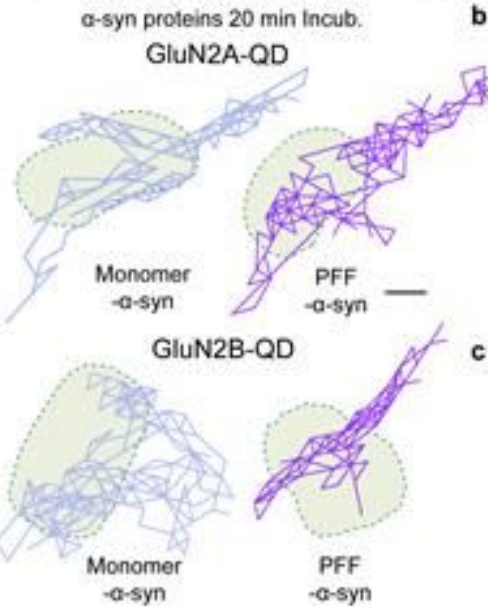

d

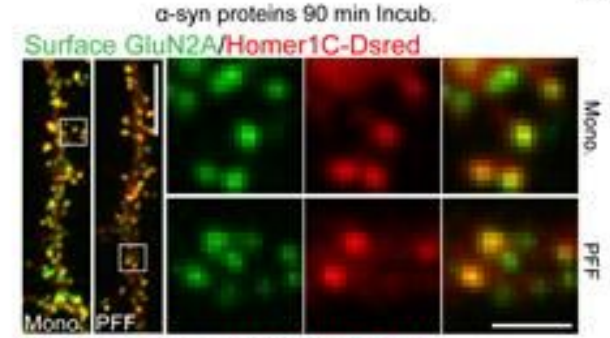

f Surface GluN2B/Homer1C-Dsred

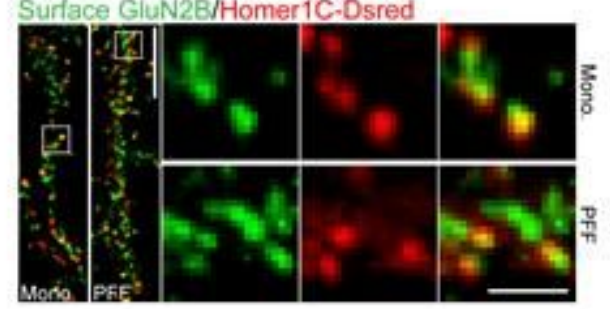

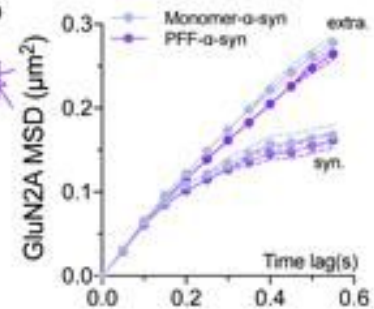
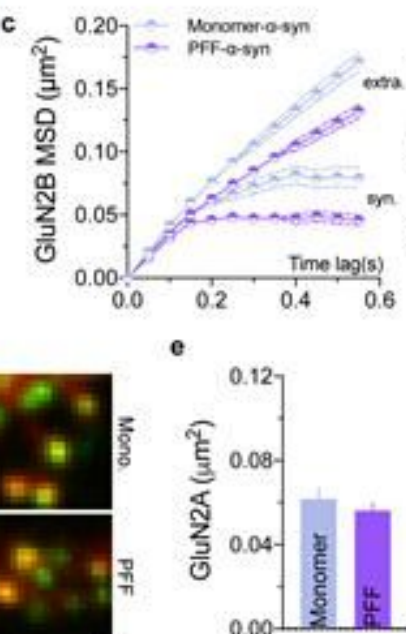

g

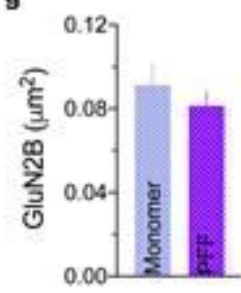

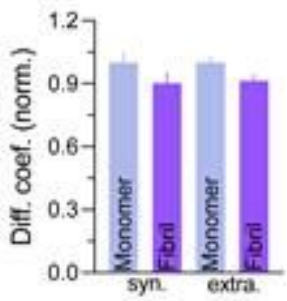

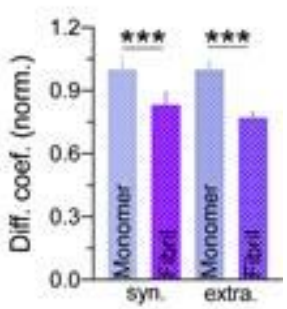

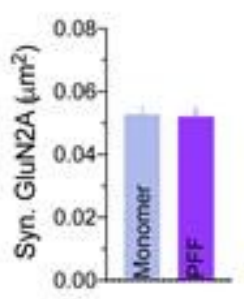

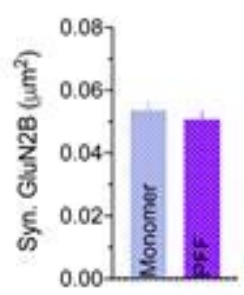

h

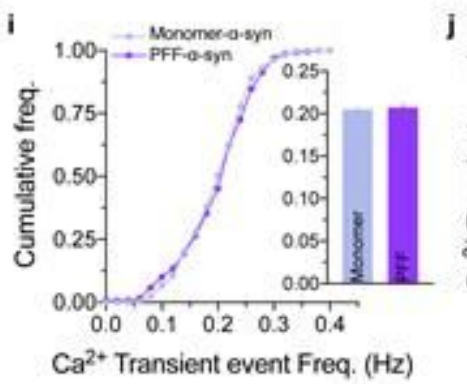

+ D-AP5

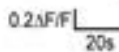

$\mathrm{Ca}^{2+}$ Transient event Freq. $(\mathrm{Hz})$

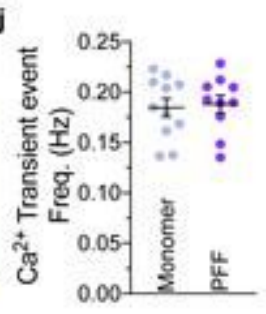




\section{Figure 5}

a-syn PFF specifically impairs the membrane dynamics of GluN2B-NMDAR. a Representative surface trajectories of single QD-coupled GluN2A-/GluN2B-NMDAR in the synaptic area after incubation with asyn proteins (monomers or PFFs) for 20 min (scale $=200 \mathrm{~nm}$ ). b The MSD of surface (synaptic and extrasynaptic) GluN2A-QD trajectories in the presence of a-syn monomers (light blue) or PFFs (violent). Right panel: The mean diffusion coefficient of synaptic and extra-synaptic GluN2A-QD (synaptic: nMonomer = 435 trajectories, $\mathrm{nPFF}=429$ trajectories; $\mathrm{p}=0.3150$; extra-synaptic: $\mathrm{nMonomer}=1022$ trajectories, $\mathrm{nPFF}$ = 995 trajectories, $p=0.0665$, Mann Whitney test). $c$ The MSD of surface GluN2B-QD trajectories as in (B). Right panel: The mean diffusion coefficient of synaptic and extra-synaptic GluN2B-QD (synaptic: $n$ Monomer $=551$ trajectories, $\mathrm{nPFF}=647$ trajectories, $* \star \star p=0.0005$; extra-synaptic: nMonomer $=1048$ trajectories, $n P F F=1250$ trajectories, ${ }^{\star \star *} p<0.0001$, Mann Whitney test). d GluN2A-NMDAR surface labeling in hippocampal neurons at DIV 13-14 after incubation with a-syn monomers or PFFs for 90 min (scale $=5 \mu \mathrm{m}$ ). Enlarged images of Homer1C or GluN2A clusters (right panels, scale $=1 \mu \mathrm{m}$ ). $\mathrm{e}$ Comparisons of surface and synaptic GluN2A cluster area (nMonomer $=90$ segments, nPFF $=87$ segments, $p=0.9948 ; p=0.9422$, Mann Whitney test). $f$ Surface labeling of GluN2B-NMDAR as in (D) $($ scale $=5 \mu \mathrm{m})$. Enlarged Homer1C or GluN2B cluster images (right panels, scale $=1 \mu \mathrm{m}) . \mathrm{g}$ Comparisons of surface and synaptic GluN2B cluster areas (nMonomer $=90$ segments, nPFF $=90$ segments, $p=$ $0.5984 ; p=0.3764$ ). $h$ Representative NMDAR-mediated calcium transients recorded (expressed as $\Delta F / F$ ratio) on neurons after incubation with a-syn monomers or PFFs for 90 min. Notably, all the events were abolished by the NMDAR-competitive antagonist D-AP5 $(50 \mu \mathrm{M})$. i Left panel: The frequency distributions of calcium transient events of spinal neurons incubated with a-syn monomers or PFFs for 90 min. Right panel: The mean calcium transient frequencies of all the spines in the respective conditions (nMonomer = 248 spines, $n P F F=235$ spines, $p=0.3910$, Mann Whitney test). $j$ The mean calcium transient frequency of each neuron in the respective conditions (nMonomer $=11$ cells, $n P F F=12$ cells, $p=0.8633$, Mann Whitney test). The results in (b), (c), (e), (g), (i right), and (j) are expressed as mean \pm SEM. 
Fig. 6 Chronic exposure of neurons to PFF $\alpha$-syn decreases NMDAR content and function.

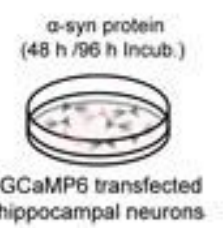

NMDAR-Ca** Transient $96 \mathrm{~h}$ a-syn incub.

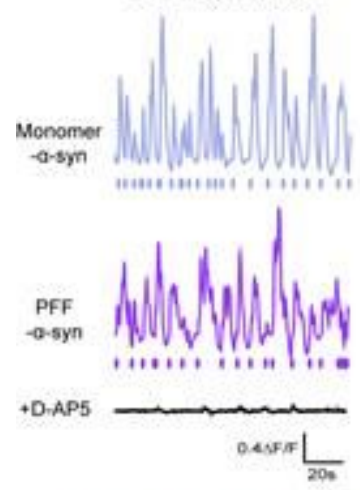

e

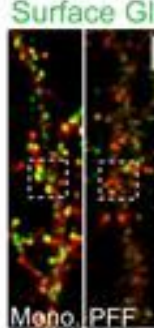

g

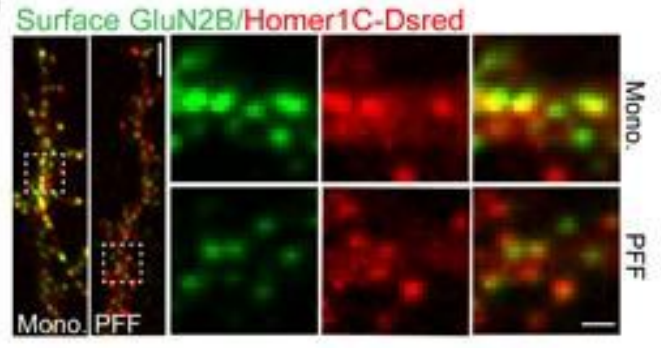

$48 \mathrm{~h}$

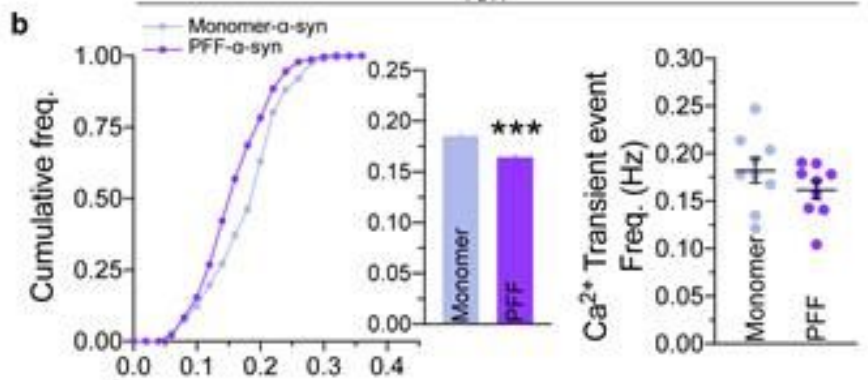

$\mathrm{Ca}^{2+}$ Transient event Freq. $(\mathrm{Hz})$

d

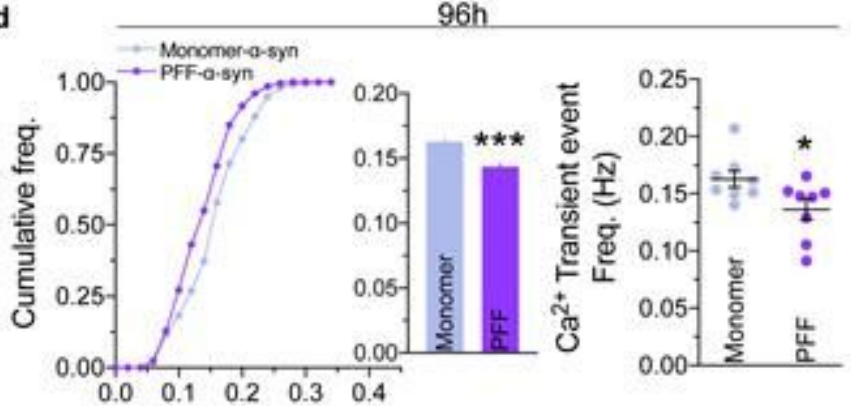

$\mathrm{Ca}^{2+}$ Transient event Freq. $(\mathrm{Hz})$

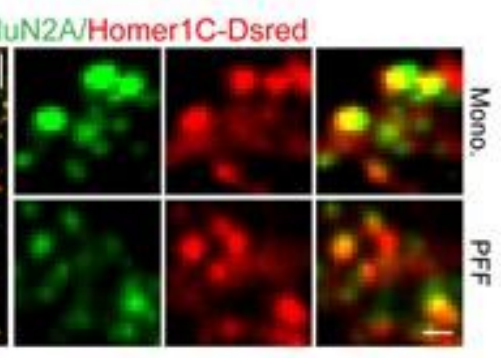

h
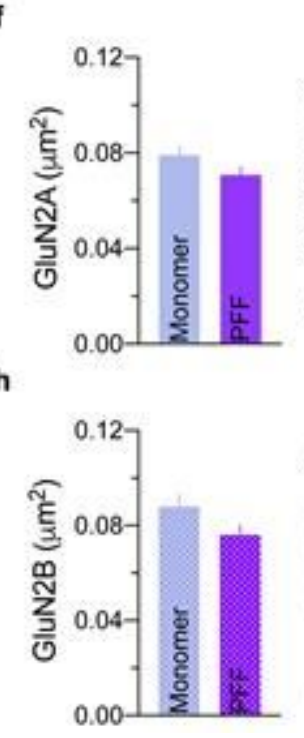
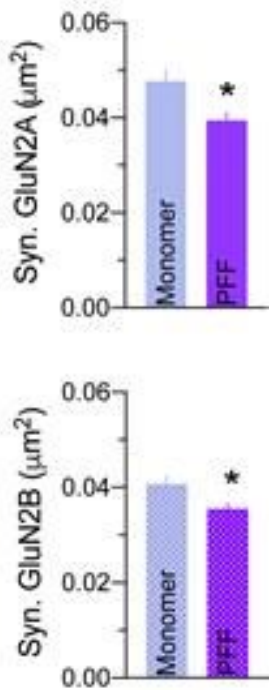

\section{Figure 6}

Chronic exposure of neurons to PFF a-syn decreases NMDAR content and function. a Diagram representing pre-calcium imaging neuron treatments. $b$ Recorded calcium transients after incubation with a-syn monomers or PFFs for $48 \mathrm{~h}$. Left panel: The frequency distribution of calcium transients and the mean calcium transient frequencies of spines (nMonomer $=279$ spines, nPFF $=332$ spines, ${ }^{\star * \star} \mathrm{p}<$ 0.0001). Right panel: The mean calcium transient frequency of each neuron in the respective conditions (nMonomer $=9$ cells, $\mathrm{nPFF}=9$ cells; $\mathrm{p}=0.2973$, Mann Whitney test). $\mathrm{c}$ Representative NMDAR-mediated calcium transients recorded (expressed as $\triangle F / F$ ratio) in neurons treated with a-syn monomers or PFFs for $96 \mathrm{~h}$. Notably, all events were abolished by the NMDAR-competitive antagonist D-AP5 $(50 \mu \mathrm{M})$. d Recorded calcium transients after incubation with a-syn monomers or PFFs for $96 \mathrm{~h}$. Left panel: 
Frequency distribution of calcium transients and mean calcium transient frequencies of spines (nMonomer $=257$ spines, nPFF $=287$ spines, ${ }^{\star \star \star} \mathrm{p}<0.0001$ ). Right panel: The mean calcium transient frequencies of each neuron in the respective conditions ( $\mathrm{nMonomer}=8 \mathrm{cells}, \mathrm{nPFF}=8 \mathrm{cells}$; ${ }^{*} \mathrm{p}=0.0379$, Mann Whitney test). e GluN2A-NMDAR surface labeling in hippocampal neurons at DIV 13-14 after incubation with a-syn monomers or PFFs for $96 \mathrm{~h}$ (scale $=5 \mu \mathrm{m}$ ). Enlarged Homer1C or GluN2A cluster images (right panels, scale $=1 \mu \mathrm{m}$ ). $\mathrm{f}$ Comparisons of surface and synaptic GluN2A cluster area (nMonomer $=70$ segments, $n P F F=60$ segments; $p=0.2193 ;{ }^{*} p=0.0300$, Mann Whitney test). g GluN2BNMDAR surface labeling (scale $=5 \mu \mathrm{m}$ ) as in (e). Enlarged Homer1C or GluN2B cluster images (right panels, scale $=1 \mu \mathrm{m}$ ). $\mathrm{h}$ Comparisons of surface and synaptic GluN2B cluster areas. (nMonomer $=78$ segments, $n P F F=89$ segments, $p=0.0957 ;{ }^{*} p=0.0423$, Mann Whitney test). The results in (b), (d), (f), and $(h)$ are expressed as mean \pm SEM.

Fig. 7 Deficits of GluN2A- and GluN2B-NMDARs in the hippocampus of A53T- $\alpha$-syn transgenic mice

a

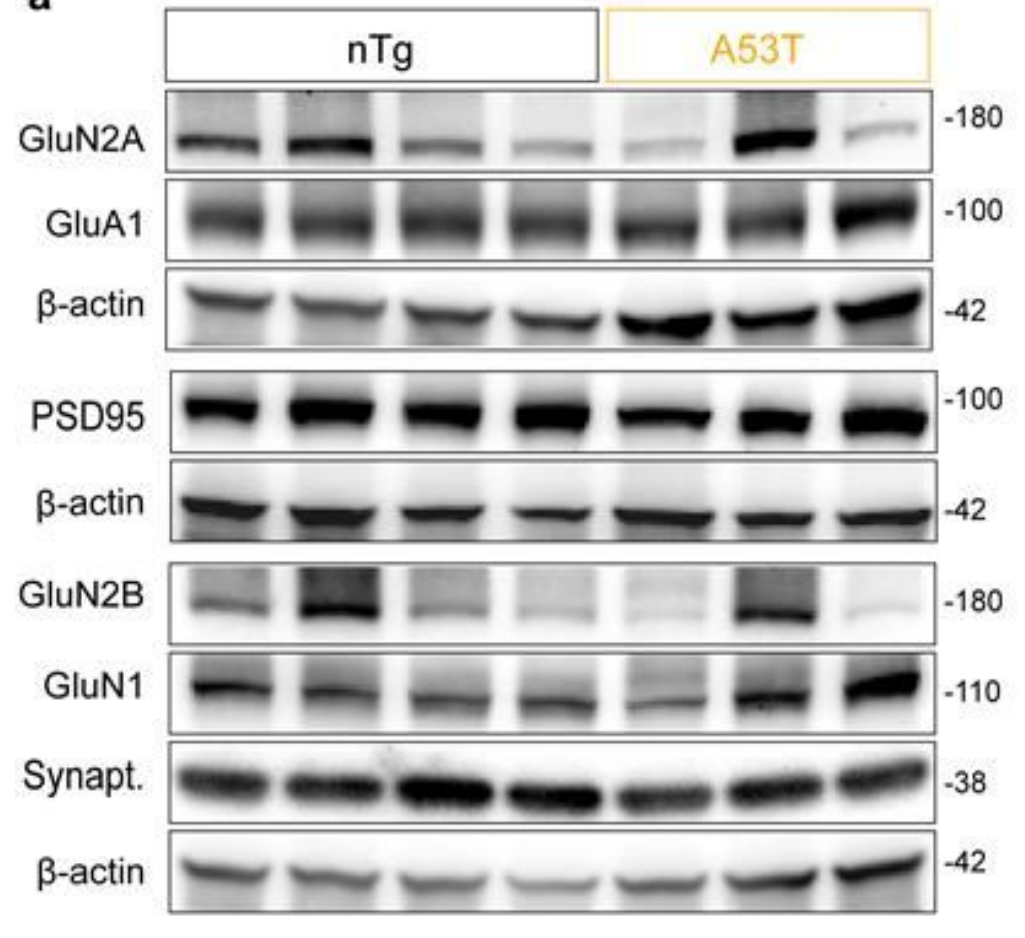

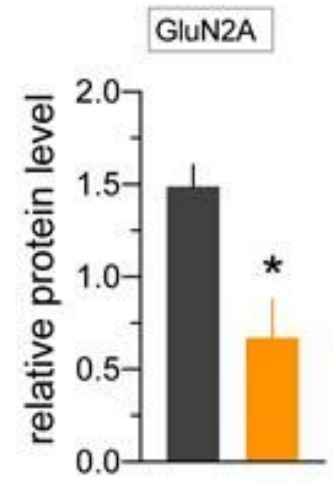

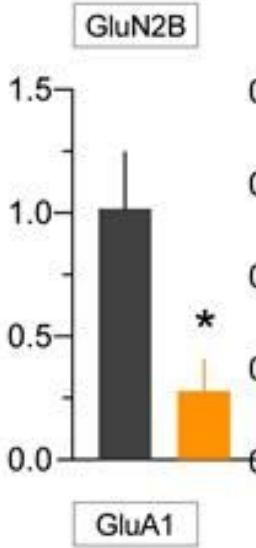

GluN2B
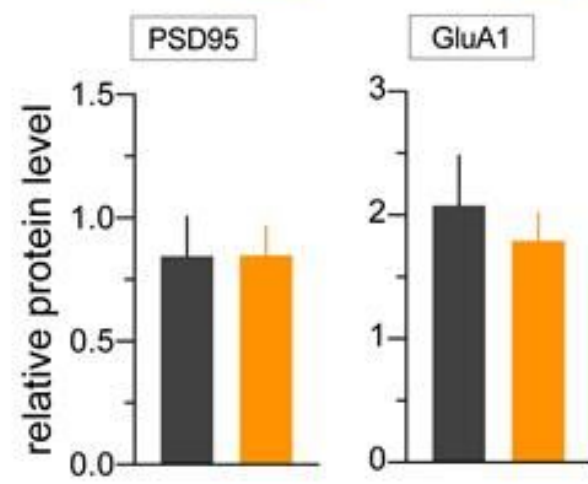

GluN1
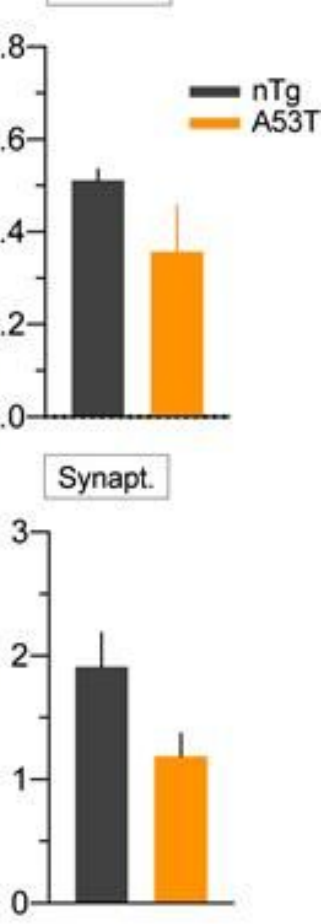
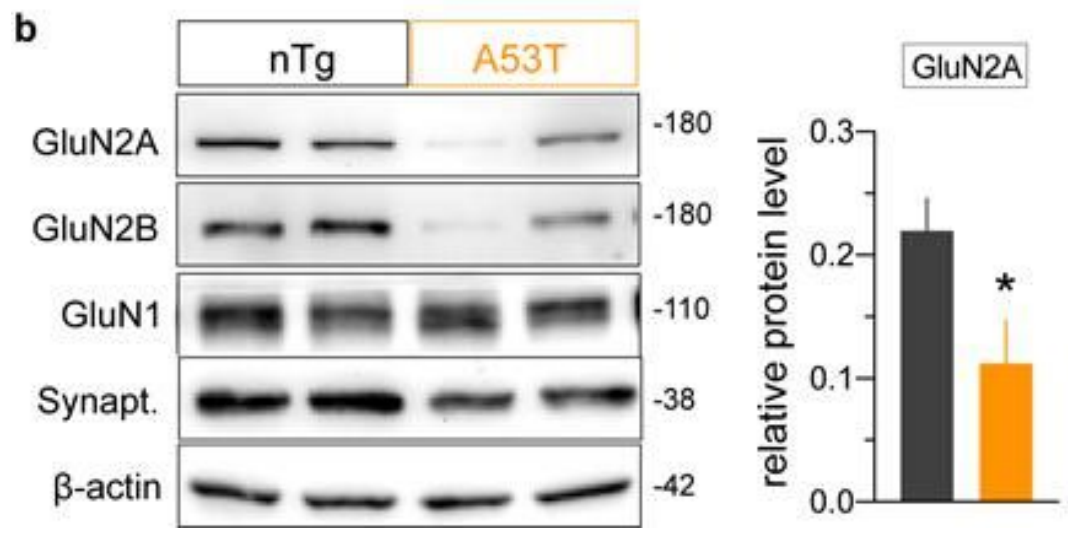

GluN2B

GluN1

Synapt.
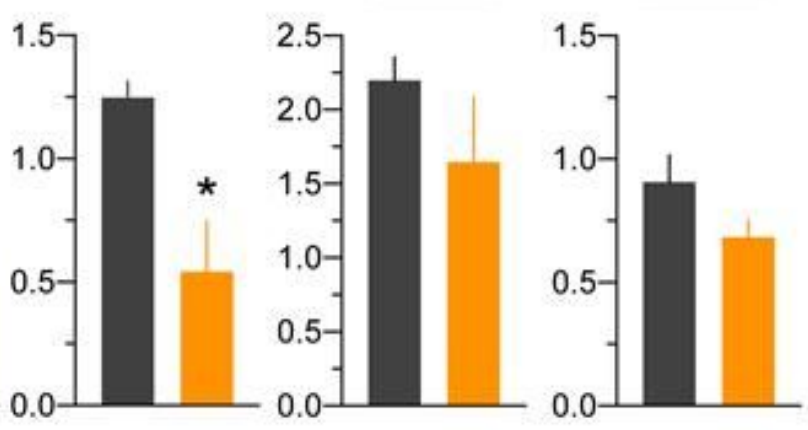

Figure 7 
GluN2A- and GluN2B-NMDAR deficits in the hippocampus of A53T-a-syn transgenic mice. a Proteins were extracted from the hippocampus of WT and A53T transgenic mice (10 M). We probed $25 \mathrm{mg}$ protein against GluN2A, GluN2B, GluN1, PSD95, GluA1, and synaptophysin. $\beta$-actin was used as the loading control. Protein level quantification ( $n W T=4$ mice, $n$ A53T $=3$ mice, ${ }^{\star} p=0.0145 ;{ }^{*} p=0.0478 ; p=0.1406$; $p=0.9971 ; p=0.5663 ; p=0.0933$, Unpaired $t$ test). $b$ Synaptosomes were purified from the hippocampus of WT and A53T transgenic mice (10 M). We probed $15 \mathrm{mg}$ protein against GluN2A, GluN2B, GluN1, and synaptophysin. $\beta$-actin was used as the loading control. Protein level quantifications ( $\mathrm{nWT}=4$ mice, $n A 53 T=4$ mice, ${ }^{*} p=0.0483 ;{ }^{*} p=0.0307 ; p=0.3008 ; p=0.1769$, Unpaired $t$ test). Data are expressed as mean \pm SEM.

Fig. 8 Modulation GluN2B-NMDAR surface dynamics rescues $\alpha$-syn-mediated effect.

a

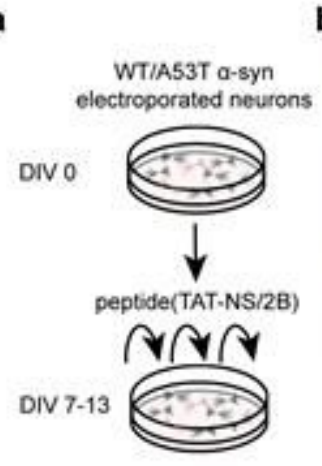

b a-syn/Homer1C-Dsred

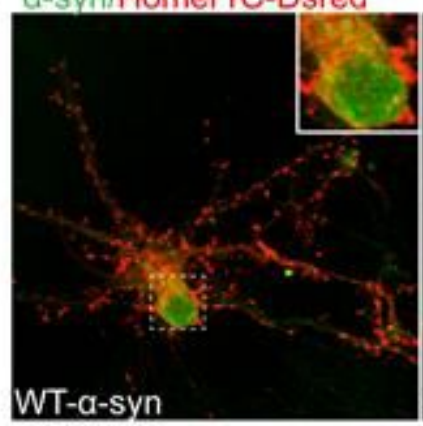

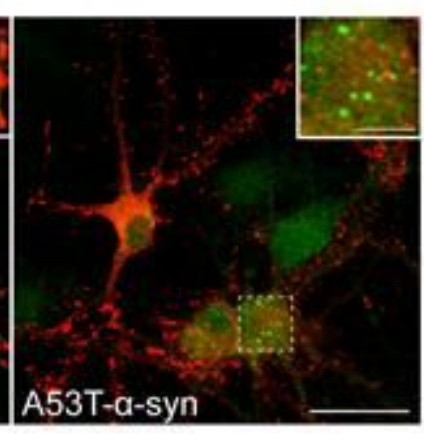

d Synaptophysin Homer1C-Dsred
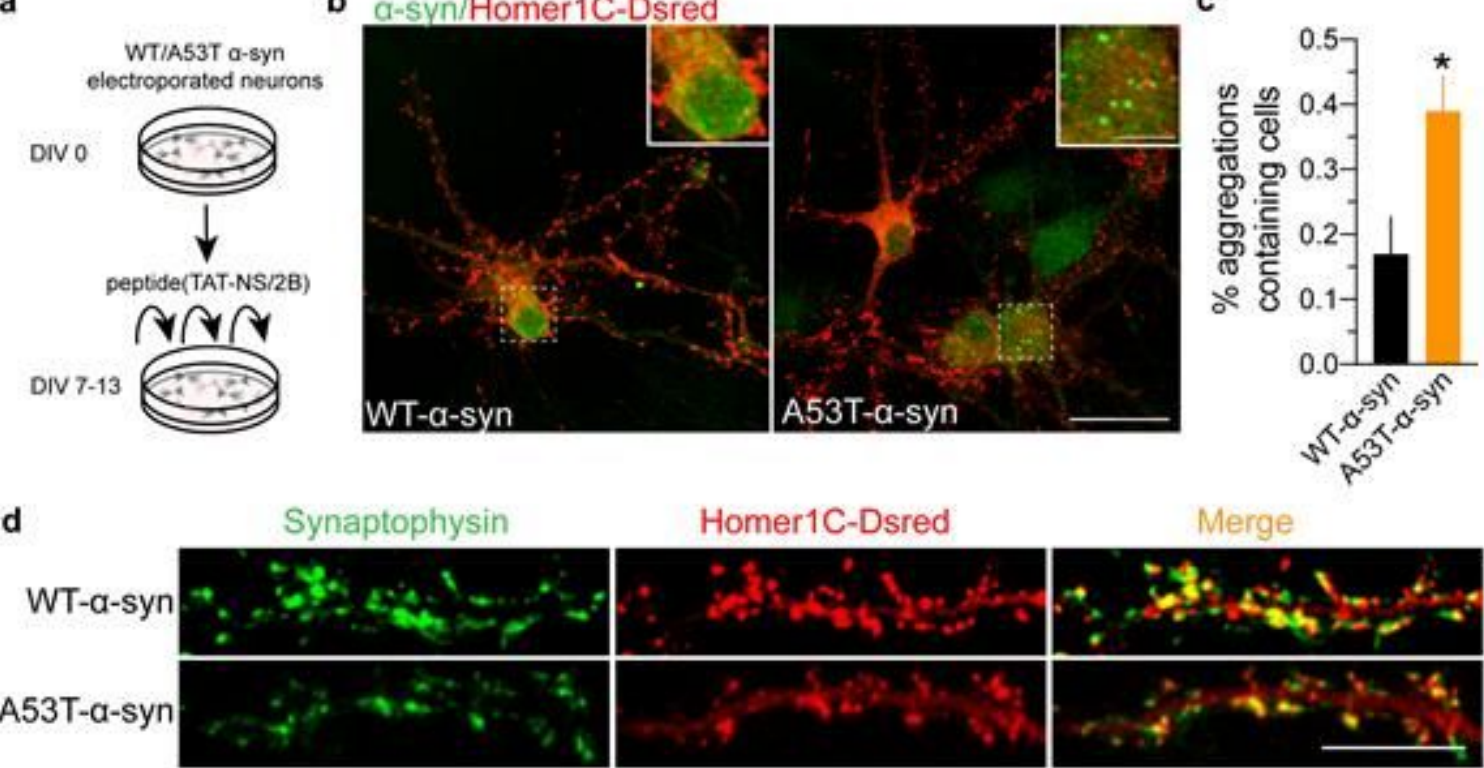

Merge

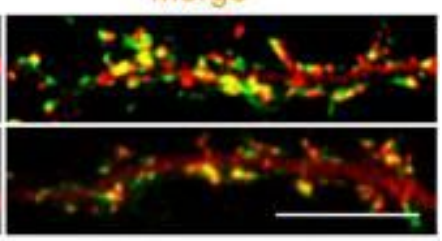

A53T- $\alpha-s y n$ transfected neurons
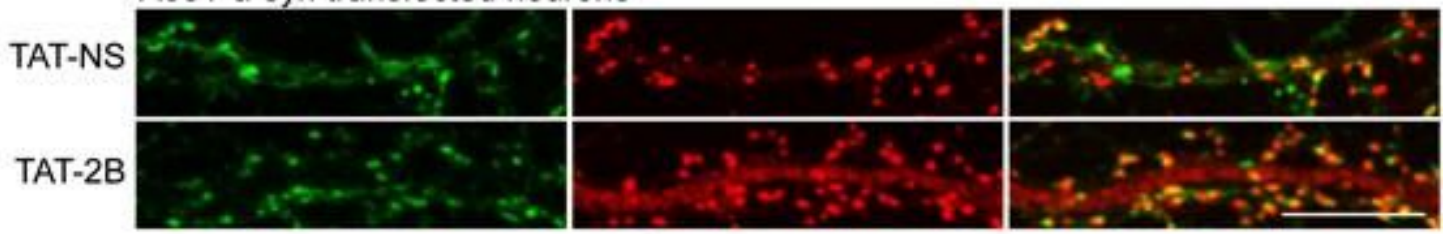

e
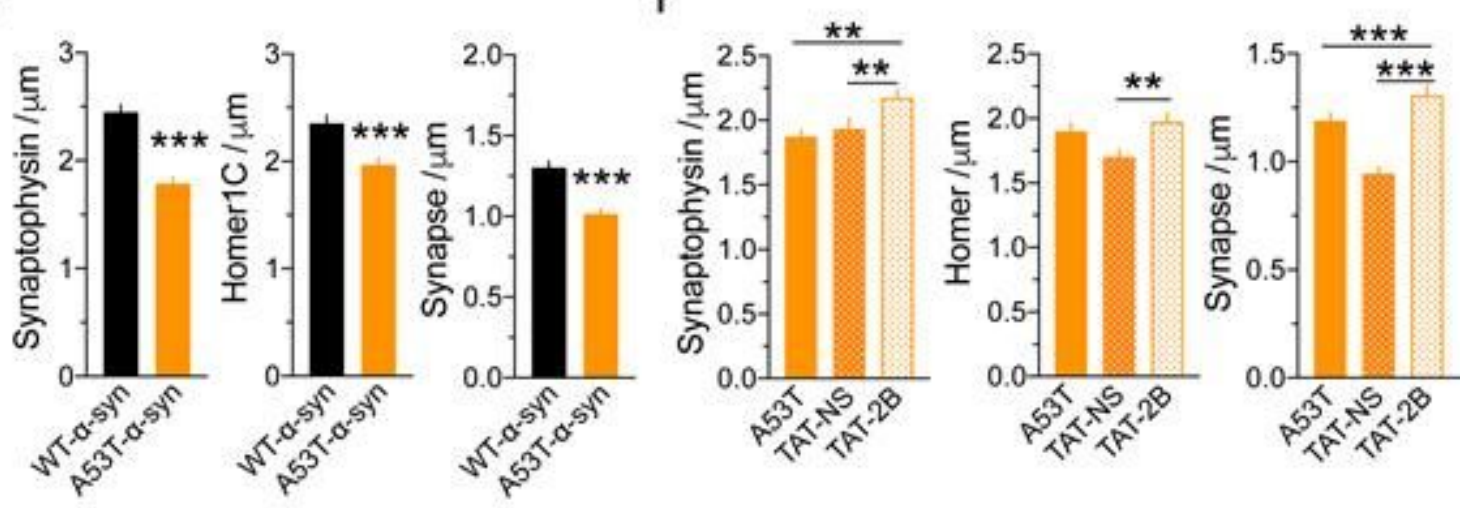

Figure 8 
Modulation of GluN2B-NMDAR surface dynamics rescues the a-syn-mediated effects. a Diagram representing dissociated neurons, which were electroporated, transfected with WT-/A53T-a-syn, and administrated with peptides (TAT-NS/2B) every other day at DIV 7-13. b a-Syn immunostaining in WT-/A53T a-syn-expressing neurons co-transfected with Homer1C-Dsred (scale $=20 \mu \mathrm{m}$ ) for 14 days. An enlarged image showing nuclear accumulation of a-syn (in A53T-a-syn condition) in the transfected neurons (scale $=5 \mu \mathrm{m}$ ). c Quantification of cell percentage containing a-syn aggregates of the total cells (nWT-a-syn $=450$ cells, nA53T- $a-s y n=455$ cells, ${ }^{*} p=0.0479$, Unpaired t test). $d$ Upper panel:

Immunostaining of synaptophysin and Homer1C in WT-/A53T-a-syn-expressing neurons for 14 days. Lower panel: Synaptophysin and Homer1C immunostaining in A53T-a-syn-expressing neurons for 14 days with peptide administration (NS-TAT or 2B-TAT) $($ scale $=5 \mu \mathrm{m})$. e Linear density of synaptophysin and Homer1C clusters and synapses (measured by overlapping synaptophysin and Homer1C clusters) in WT-/A53T- $a$-syn conditions ( $n W T-a-s y n=100$ segments, nA53T- $a-s y n=97$ segments; $* \star \star p<0.0001$, Mann Whitney test, scale $=5 \mu \mathrm{m})$. $\mathrm{f}$ Linear density of clusters, including synaptophysin, Homer1C, and synapses, in A53T a-syn-expressing neurons administrated with peptides. ( $\mathrm{n}$ A53T $=104$ segments, nTATNS $=104$ segments, $n T A T-2 B=105$ segments, $* * p=0.0028 ; * \star p=0.0004 ; * \star \star p<0.0001$, Kruskal-Wallis test followed by Dunn's Multiple Comparison test, scale $=5 \mu \mathrm{m})$. The results in (c), (e), and (f) are expressed as mean \pm SEM.

\section{Supplementary Files}

This is a list of supplementary files associated with this preprint. Click to download.

- supplementfigure6.tif

- supplementfigure5.tif

- supplementfigure4.tif

- supplementfigure3.tif

- supplementfigure2.tif

- supplementfigure1.tif 